\title{
Structural Analysis of Sol-Gel Derived TiO2 Nanoparticles: A Critical Impact of TiO2 Nanoparticles on Thermo-Mechanical Mechanism of Glass Fiber Polymer Composites
}

\section{Avinash Kumar}

NIT Silchar: National Institute of Technology Silchar

\section{Abir Saha}

IIT Guwahati: Indian Institute of Technology Guwahati

Santosh Kumar ( $\sim$ santosshhh@gmail.com )

NIT Silchar: National Institute of Technology Silchar https://orcid.org/0000-0002-1831-8805

\section{Research Article}

Keywords: TiO2 nanoparticles, Sol-gel method, Physical properties, Mechanical properties, Microstructure analysis, Glass fiber

Posted Date: May 21st, 2021

DOl: https://doi.org/10.21203/rs.3.rs-539836/v1

License: (c) (1) This work is licensed under a Creative Commons Attribution 4.0 International License. 


\title{
Structural analysis of sol-gel derived $\mathrm{TiO}_{2}$ nanoparticles: A critical impact of $\mathrm{TiO}_{2}$ nanoparticles on thermo-mechanical mechanism of glass fiber polymer composites
}

\author{
Avinash Kumar ${ }^{1}$, Abir Saha ${ }^{2}$, Santosh Kumar ${ }^{1 *}$ \\ ${ }^{1}$ Department of Mechanical Engineering, National Institute of Technology Silchar, Assam, \\ 7888010, India \\ ${ }^{2}$ Department of Mechanical Engineering, Indian Institute of Technology Guwahati, Assam, \\ 781039, India \\ *Corresponding author email: santosshhh@gmail.com
}

\begin{abstract}
The incorporated of inorganic nanoparticles with thermosetting epoxy polymer are an emerging field of research over past few years. It is well analyzed that epoxy matrix are brittle in nature that shows poor crack initiation and propagation and results poor thermo-mechanical properties. Therefore, researchers are showing their interest towards nanoparticles embedded epoxy composites to improve their fracture resistance (brittleness and toughness). In this investigation, the dispersion of $\mathrm{TiO}_{2}$ nanoparticles at different weight fraction (0-2\%) with glass fiber reinforced epoxy composites is performed to enhance structural and thermo-mechanical properties. The $\mathrm{TiO}_{2}$ nanoparticles are prepared by sol-gel method and structural analysis of $\mathrm{TiO}_{2}$ nanoparticles shows greater interfacial bond with epoxy matrix and glass fibers due to fine dispersion of nanoparticles. From obtained results, a significant enhancement in their tensile strength $(38.56 \%)$, flexural strength $(30.52 \%)$, inter-laminar shear stress $(25.22 \%)$, impact strength (327.10\%), micro-hardness $(48.53 \%)$ and fracture energy $(40.19 \%)$ with minimum detrimental effect on toughness was revealed for GFRP-T1.0 compare to GFRP-T0.0 composite laminates. The stiffness and rigidity also improved up to $52.72 \%$ and $34.13 \%$ respectively for GFRP-T1.5 compare to GFRP-T0.0 composite laminates. The effects of nanoparticles contents and clustering size on thermal stability and glass transition temperature of developed composites are observed by thermo-gravimetric analysis. The surface morphology of $\mathrm{TiO}_{2}$ nanoparticles are characterized by transmission electron microscope (TEM) while dispersion of nanoparticles and failure of developed composites were analyzed by scanning electron microscopy (SEM).
\end{abstract}

Keywords: $\mathrm{TiO}_{2}$ nanoparticles; Sol-gel method; Physical properties; Mechanical properties; Microstructure analysis; Glass fiber 


\section{Introduction}

The advance composite materials made from continues fiber polymer matrix composite laminates with different orientation and arrangements comprise a successful structural materials due to their less density, better specific strength and stiffness, lower thermal coefficient, high fatigue and damping resistance for various industrial application like construction, aerospace, marine, automobile and biomedical [1]. Fiber reinforced polymeric composites (FRPCs) such as glass fiber and carbon fiber have attracted much awareness as a substitute for conventional materials like wood, steel and plastics for various structural applications. The replacement of concrete structure with FRPCs gave more flexibility and suitability to the industrial society and has been also highlighted by American concrete institute (ACI) committee-503 where the adhesion and bonding between fibers and matrix acts a crucial role on the overall performance of the materials [2,3]. Although, carbon fiber is not available plenty due to its more expensive and low reusability with high design and manufacturing cost, so glass fiber reinforced polymeric composite (GFRP) can be a better alternative materials for construction, automotive, marine, aerospace, wind turbine and power plants that also posses excellent chemical, physical and thermo-mechanical properties [4].

Thermoset epoxy resins are commonly used polymeric matrix for fabricating high performance and flexible composite due to their higher durability, better thermal stability and superior chemical, electrical, and mechanical properties [5, 6]. However, epoxy resins have highly brittle in nature that require high fracture and impact strength. Therefore, to overcome these disadvantages, incorporating or reinforcing fibers/fillers into polymer matrix enhanced the strength and stiffness of the composite without disclaiming its toughness [7]. To improve the performance and properties of FRPCs, nanoparticles were incorporated to identify as a prospective solution. A broad range of nanoparticles such as silica, clay, calcium carbonate, nickel oxide, layered silicate, titanium dioxide etc. have gained particular interest for inorganic/organic nanocomposites [8]. The impact of nanoparticles on the developed composite has been studied and investigated their performance including $\mathrm{TiO}_{2}$ spherical nanoparticles [9], carbon oxide dots [10], carbon nanotubes [11], nanoclays [12], dichalcogenides transition metal [13], and graphene [14]. The several researches have been conducted on metallic or inorganic nanoparticles that explained about their performance and revealed an excellent candidate to reinforce with polymeric materials mainly thermosetting epoxy resin for better mechanical, 
thermal and electrical properties [15]. Among various inorganic nanoparticles, $\mathrm{TiO}_{2}$ has nontoxic, lower in cost, superior refractive index, and chemical inertness that attendant higher intent towards research and have been used for different commercial applications such as antibacterial activities, inhibition, photo electric and photo catalytic conversion in solar cells as well as utilized in food additives, self cleaning, corrosion resistant coating, water and air purification etc [16-18]. Therefore, $\mathrm{TiO}_{2}$ nanoparticles have been recognized as premising reinforced materials to develop effective composite materials due to their light density, higher mechanical and thermal properties, reduce ultraviolet and thermal degradation [19-21]. Several investigations examined that, the performance and efficiency of the developed composites have been influenced with volume contents, shape and size that enhanced the thermal, mechanical, fatigue and toughness properties [22, 23] while greater surface area of nanoparticles makes chemically very active to bond with matrix materials [1]. However, these nanoparticles have been agglomerated and incompatibility with polymer matrix due to large surface area to volume ratio that results improper bonding and reduce their respective properties [8, 24]. Therefore, hybridization of these nanoparticles with different fiber reinforced materials was identified as potential solution that enhanced their compatibility and increases the durability of the materials where a low amount of homogeneous dispersion of nanoparticles with GFRP composites demonstrated higher mechanical, thermal, and fracture properties as well as improved their glass transition temperature $\left(\mathrm{T}_{\mathrm{g}}\right)$ and maximum decomposition temperature $[22,25,26]$.

Therefore, the current study deals with structure analysis of $\mathrm{TiO}_{2}$ and the effects of nanoparticles at different weight fraction on thermo-mechanical characterization of GFRP composites have been examined. The $\mathrm{TiO}_{2}$ nanoparticles are prepared by sol-gel methods for better dispersion with epoxy matrix and GFRP composites laminates are fabricated with vacuum assisted resin infusion molding techniques (VARIM).

\section{Materials and methods}

The bidirectional E-glass fiber was used for reinforcements that were purchased from Surfland Composites Pvt. Ltd. Bangalore, India. The E-glass fiber was having a density of $180 \mathrm{~g} / \mathrm{m}^{2}$ with a 5-7micrometre diameter. Araldite LY556 (Diglycidyl either of bisphenol, density 1.15-1.20g/cc and epoxy content $\sim 5.30-5.45 \mathrm{eq} / \mathrm{kg}$ ), HY 906 (methylnadic anhydride, density $1.20-1.25 \mathrm{~g} / \mathrm{cc}$ ) and DY 070 (density 0.95-1.05gm/cc) were used as resin, hardener and accelerator respectively as a 
matrix material for fabrication of GFRP composites that were purchased from Huntsman International Pvt. Ltd. Mumbai, India.

For preparation and synthesis of titanium dioxide $\left(\mathrm{TiO}_{2}\right)$ by sol-gel method, Titanium Isopropoxide $\left(\mathrm{C}_{12} \mathrm{H}_{28} \mathrm{O}_{4} \mathrm{Ti}\right)$ having density- $0.96 \mathrm{gm} / \mathrm{ml}$, molecular weight $-284.22 \mathrm{~g} / \mathrm{mol}$ and Isopropanol as a liquid precursor were used that purchased from Sisco Research Laboratories Pvt. Ltd. Mumbai, India. $\mathrm{TiO}_{2}$ nanoparticles were dispersed in resin solution then the solution was prepared with help of proper mixing from proper mechanical stirring then, ultrasonication was done for proper dispersion of nanoparticles in resin solution, then composites were fabricated with VARIM.

\subsection{Preparation of $\mathrm{TiO}_{2}$ nanoparticles}

The $\mathrm{TiO}_{2}$ nanoparticles was prepared through hydrolysis and condensation process with help of Sol-gel methods and shown in Fig. 1. Initially, 500ml distilled water having $\mathrm{pH} 7$ was taken in a beaker then, put over a hot plate magnetic stirrer. The stirring process was done at $700 \mathrm{rpm}$ and maintains $70^{\circ} \mathrm{C}$ temperature. Now, $10 \mathrm{ml}$ titanium Isopropoxide and $25 \mathrm{ml}$ Isopropanol was taken in two separate beakers. Instantly, the titanium Isopropoxide was added to Isopropanol with help of a dropper because titanium Isopropoxide was hazardous it gets react instantly when it comes in contact with moisture and finally mix it properly. The prepared solution was now added drop wise in distilled water beaker. Instantly the gel formation took place in the beaker and the hydrolysis process was started. The desired $\mathrm{pH} 2$ of the solution was attained by adding $\mathrm{HNO}_{3}$ or $\mathrm{NH}_{4} \mathrm{OH}$. Hydrolysis of the solution produced turbid solution when it was heated at $60-70^{\circ} \mathrm{C}$ for $14 \mathrm{hrs}$. The process of producing a turbid solution was called peptization. After the peptization

process, the decrement in the volume of the solution to $50 \mathrm{~cm}^{3}$ was recorded. Depending upon the preparatory conditions, the resultant solution was obtained in white colour with high viscosity. The prepared precipitates were washed with ethanol several times and then filtered with a bench top centrifuge. The prepared filtrated powders were drying in the oven for $3 \mathrm{hrs}$, at $100^{\circ} \mathrm{C}$ then powders became yellow-white colour. The final obtained powder was coarse in structure, so, mortar and pestle were used to produce fine nanoparticles of $\mathrm{TiO}_{2}$.

\subsection{Dispersion of Nanoparticles}

The proper dispersion of nanoparticles in resin solutions was the essential requirements to minimize the scatter and agglomeration in the developed composites. The following techniques such as mechanical stirring, shear mixing, acoustic cavitations, evaporation with solvent, 
ultrasonic waves, pulsed ultrasound vibration and direct in-situ incorporation with chemical and polymerization methods were used to improve the dispersion process of nanoparticles [25, 27]. In particular, it was observed that the sol-gel methods were effective to improve the bonding strength of $\mathrm{TiO}_{2}$ nanoparticles and homogeneous dispersion of nanoparticles played a vital role in improving the thermo-mechanical properties of developed composites [28, 29]. The ultrasonic is a widely used technique to avoid scatter/ agglomeration during the mixing of nanoparticles with resin and provide fine quality of filled matrix material [30]. Thus, a fine structure of the matrix enhanced the interfacial bonding strength between fibers and matrix of developed composites.

For the present study, mechanical stirring and ultrasonication techniques were adopted for superior dispersion of nanoparticles. Initially, the mechanical stirring was done for $15 \mathrm{~min}$ to prepare a mixture of $\mathrm{TiO}_{2}$ nanoparticles and resin then finally, the sonication process was used for 30min to do proper mixing and dispersion to avoid agglomerations.

\subsection{Preparation of GFRP Composite}

Glass fiber reinforced $\mathrm{TiO}_{2}$ nanoparticles with epoxy matrix composite laminates were prepared with VARIM methods and details methodology is showing in Fig. 2. For composite plate fabrication LY556, HY906 and DY090 were used as resin, hardener and accelerator respectively. The weight ratio of resin and hardener is 1:0.95 and the accelerator is taken as $2 \%$ of resin weight. An initially adequate amount of resin was taken in hard plastic, then $\mathrm{TiO}_{2}$ nanoparticles was added then, the whole resin solution (Part A) was taken for mechanical mixing for 15 min. Then slurry of (resin $+\mathrm{TiO}_{2}$ nanoparticles) was then processed for ultrasonic dual mixing process (UDM) with simultaneous stirring by the impeller for proper dispersion of nanoparticles in a resin solution. After the dispersion of nanoparticles, hardener and accelerator were added into the solution (Part A) in a stoichiometric ratio. Then the mixture was again put under mechanical stirring action for 10 minutes for proper mixing. After that, the whole mixture is put inside desiccators to remove the gas or void entrapped into the solution during mixing. The prepared mixture was used for the fabrication of composite plates by the VARIM process.

Vacuum-assisted resin infusion techniques have become popular in the manufacturing of

these composites to produce high-quality large-scale products where the process was well controlled, may produce composite plates with less than $1 \%$ voids. For this study, the single-side mould surface was taken and then dry release film (or peel ply) were placed on the mould 
surface. Now, eight layers of glass fiber mats were arranged and cover on both side with peel ply then mesh was placed over the top surfaces of this arraignment for better flow of resin solution with high permeability inside the composite's laminates. The vacuum was created over the mould and the resin solution is infused with help of a vacuum pump where the resin solution was spread over the entire surface of the mould. The peel ply was used for superior smoothness and easy removal of composite plates from the mould surface. Finally, the prepared composite plate was taken from the mould and put inside an oven at $120^{\circ} \mathrm{C}$ for 2 hours called pre-curing and then post-curing of composite plates at $160^{\circ} \mathrm{C}$ for 6 hours. The prepared composite plates were cut as per ASTM standard for various testing.

\section{Characterization and testing}

\subsection{Characterization of $\mathrm{TiO}_{2}$ nanoparticles}

\subsubsection{Structural characterization}

The physical structure of the nanoparticles was observed by Burcker D8 focus X-Ray diffraction machine (XRD), operated at a voltage of $30 \mathrm{kv} / 15 \mathrm{~mA}$ with cu radiation at an angle of $2 \Theta$ from 5 to 75. The weight loss of nanoparticles at increasing temperature was analyzed by EXSTAR TGA/DTA 6300 Thermo-gravimetric analyzer, where nanoparticles was heated with a controlled heat flow rate of $10^{\circ} \mathrm{C} / \mathrm{min}$ at nitrogen environment. To understand the functional groups (chemically) present in nanoparticles, the powder was going through Fourier transform infra-red (FTIR) spectrometer of PerkinElmer Spectrum machine in the range of $500-4000 \mathrm{~cm}^{-1}$ at a resolution of $4 \mathrm{~cm}^{-1}$.

\subsubsection{Surface morphological analysis}

The surface morphology of $\mathrm{TiO}_{2}$ nanoparticles was examined by transmission electron microscope (TEM) Philips, CM 200 operating voltages: 20-200kv with resolution:2.4 at room temperature. TEM is a microscopy technique in which specimen passed through electron beam and transmitted in the form of an image. TEM analysis is used for high resolution imaging compare to light microscopy. The microstructure and dispersion of $\mathrm{TiO}_{2}$ nanoparticles were characterized with help of field emission scanning electron microscopy (FESEM). FESEM was conducted on Quanta 200 with 15kVvolatege at room temperature. The FESEM analysis was mainly used to characterize the dispersion and scattering of $\mathrm{TiO}_{2}$ nanoparticles under high magnification of $1000 \mathrm{x}$ to $5000 \mathrm{x}$.

\subsection{Characterization of composite laminates}




\subsubsection{Mechanical characterization}

The tensile testing was performed by using a $50 \mathrm{kN}$ Instron, 8801 universal testing (UTM) machine. The test sample was prepared as per ASTM (D-638) [31] standard with a dimension of $160 \times 15 \times 3 \mathrm{~mm}$ and testing has been done at $1 \mathrm{~mm} / \mathrm{min}$ of cross speed with a gauge length of 60 $\mathrm{mm}$. The five specimens of each weight fraction were tested and the average value with an error bar has been reported in the graphical representation. The testing was carried under quasi-static tensile loading condition at room temperature $\left(23^{\circ} \mathrm{C}\right)$, and the modulus of elasticity, yield strength, ultimate tensile strength and strain at failure of specimens at maximum load were measured.

The three-point bending test (also known as flexural test) was carried out by using a similar universal testing machine, INSTRON, 8801. The five samples of each weight fractions following ASTM D 790 [32] standards with a dimension of $130 \times 14 \times 3 \mathrm{~mm}$ were tested and the average value was reported. The three-point bending test was conducted at $1 \mathrm{~mm} / \mathrm{min}$ of cross speed and a span length of $60 \mathrm{~mm}$ under quasi-static loading condition at room temperature and the flexural modulus, ultimate flexural strength, maximum deflection before the break of specimens at maximum load were measured.

The micro-hardness testing of the developed composite was done with the help of Vickers micro-hardness tester and following standard ASTM D384-99 [33]. The five different surface positions of each type of sample have been tested and the average value has been presented graphically.

The Charpy impact testing of the developed composite was carried out with the help of a Charpy impact tester made by FIE (Fuel Instruments and Engineers Pvt. Ltd.). The five notched samples of each weight fraction were tested and the average test result was adopted. The ASTM D256-10 [34] standard was followed for preparing the test samples. The dimension of the impact test specimen was $63.5 \mathrm{~mm} \times 12.7 \mathrm{~mm} \times 3.2 \mathrm{~mm}$ and the depth of the notch was $2.54 \mathrm{~mm}$.

The degree of fiber-matrix interfacial adhesiveness was evaluated by interlaminate shear test (also known as short beam shear test). To perform the short beam test, the previously mentioned UTM machine was used and samples were cut as ASTM D2344 [35] standard at room temperature $\left(23^{\circ} \mathrm{C}\right)$. The dimension of the test sample was $37 \mathrm{~mm} \times 9 \mathrm{~mm} \times 4.5 \mathrm{~mm}$ and the strain rate was maintained at $1 \mathrm{~mm} / \mathrm{min}$. The five samples of each type of composites were tested and the average result has been reported. 
The plane strain fracture toughness of the developed composites was investigated by using the previously mentioned UTM machine and following ASTM standard ASTM D504599b. The five specimens of each weight fraction composites with single edge notched were tested with a crosshead speed of $10 \mathrm{~mm} / \mathrm{min}$ and the average date has been reported. The fracture energy of each type of composite was found by using equation (1) mentioned below [36].

$$
G_{I C}=\frac{U}{B W_{\varphi}}
$$

Where $G_{I C}=$ fracture energy, $U=$ corrected energy, $B=$ thickness of the specimen, $\mathrm{W}=$ width of the specimen and $\varphi=$ energy calibration factor.

\subsubsection{Thermal stability}

To understand the thermal stability and degradation behavior with glass transaction temperature of the developed composites, Thermo gravimetric analysis (TGA) and Differential thermal analysis (DTA) were performed. The weight loss of the composites under the influence of temperature and maximum degradation temperature were characterized with help of EXSTAR TGA/DTA 6300 Thermo-gravimetric analyzer. The test was carried at a heating rate of $10^{\circ} \mathrm{C} / \mathrm{min}$ from $30^{\circ} \mathrm{C}$ (room temperature) to $900^{\circ} \mathrm{C}$ at nitrogen gas environment.

\subsubsection{Morphology analysis of fracture surface}

The morphology behavior of developed composites laminates at fracture surface is characterized with scanning electron microscope (SEM). SEM is conducted on Sigma 300 with voltage of 5 $\mathrm{kV}$ at room temperature and used to magnify the microstructure and morphology behavior of composites in which high electron beam is incident on the surfaces of the specimens. To pass the electron smoothly, developed composite specimens are well coated with gold/silver coating for better electrical conductivity.

\section{Result and discussion}

\subsection{Characterization of $\mathrm{TiO}_{2}$ nanoparticles}

The structural analysis of prepared $\mathrm{TiO}_{2}$ nanoparticles is characterized by performing XRD, FTIR, TEM, FESEM and TGA. Fig. 3(a) showed the XRD results of prepared $\mathrm{TiO}_{2}$ nanoparticles. The diffraction peak observed at $25.43^{\circ}, 37.88^{\circ}, 47.94^{\circ}, 53.94^{\circ}, 54.94^{\circ}, 62.58^{\circ}$ and $69.87^{\circ}$ with corresponding to the crystalline plane of (101), (004), (200), (105), (211), (204), (116) and (220) of tetragonal anatase $\mathrm{TiO}_{2}$ nanoparticles. The result confirmed that, the prepared $\mathrm{TiO}_{2}$ nanoparticles with sol-gel methods are more adequate and fine to enhance the dispersion 
qualities in the matrix materials [37]. From this diffraction pattern, Debye-Scherrer equation is used to calculate the average crystallites (grain) size of $\mathrm{TiO}_{2}$ nanoparticles [38].

$$
\mathrm{d}=\mathrm{K} \lambda / \beta \cos \theta
$$

Where $\mathrm{K}=0.89$ (Scherrer constant), $\lambda=0.15406 \mathrm{~nm}$ (the wavelength of the $\mathrm{x}$-ray source), $\beta=$ full width of the diffraction peak (radian) [39]. The average grain size of $\mathrm{TiO}_{2}$ nanoparticles is found as $8.12 \pm 0.21 \mathrm{~nm}$.

The existence of chemical structure and functional group of $\mathrm{TiO}_{2}$ nanoparticles has been examined with FTIR and measure the intensity of the $\mathrm{TiO}_{2}$ nanoparticles as shown in Fig. 3(b). Broad intensity was observed at 3420 and $1630 \mathrm{~cm}^{-1}$ due to the stretching vibration of $\mathrm{O}-\mathrm{H}$ bonding due to presence of moisture [40]. The peak at 515 and $660 \mathrm{~cm}^{-1}$ has been observed due to vibration of Ti-O-Ti bond and minor peaks at 775 and $565 \mathrm{~cm}^{-1}$ has been observed due to Ti-O bonding of Titanium dioxide [41]. Based on the FTIR spectra, the analysis has been made that the $\mathrm{TiO}_{2}$ nanoparticles can be the better inclusion for preparing composites laminates with better interfacial bonding and strength.

To identify the water content $\left(\mathrm{H}_{2} \mathrm{O}\right)$ and weight loss in prepared $\mathrm{TiO}_{2}$ nanoparticles, thermo-gravimetric analysis (TGA) and derivative thermo-gravimetric (DTG) have been performed. Two types of $\mathrm{H}_{2} \mathrm{O}$ desorption has been observed. First, $\mathrm{H}_{2} \mathrm{O}$ which is absorbed physically made a weak chemical bond with $\mathrm{TiO}_{2}$ and evaporate at $120^{\circ} \mathrm{C}$. Second, chemically absorbed $\mathrm{H}_{2} \mathrm{O}$ (also called crystallographic water). These types of $\mathrm{H}_{2} \mathrm{O}$ made a comparatively strong bond with $\mathrm{TiO}_{2}$ and evaporate at $300^{\circ} \mathrm{C}$ [42]. The weight loss and derivative weight loss of $\mathrm{TiO}_{2}$ nanoparticles with influence of temperature are shown in Fig. 3(c). From the DTG plot, one can find the points that showed the maximum weight loss rate at $118^{\circ} \mathrm{C}$ to $120^{\circ} \mathrm{C}$ and $298^{\circ} \mathrm{C}$ to $301^{\circ} \mathrm{C}$. These two peaks are due to the evaporation of physically and chemically absorbed $\mathrm{H}_{2} \mathrm{O}$. The percentages of physically and chemically absorbed $\mathrm{H}_{2} \mathrm{O}$ are $13.8 \%$ and $9.88 \%$ respectively in prepared $\mathrm{TiO}_{2}$ nanoparticles.

The shape of the prepared $\mathrm{TiO}_{2}$ nanoparticles has been observed with the help of a field emission scanning electron microscope (FESEM). Fig, 3(d) showed the microstructure behavior of $\mathrm{TiO}_{2}$ nanoparticles and analyzed that, the microscopic view of nanoparticles tends to spherical shape. The spherical shapes of nanoparticles have a positive impact on the thermo-mechanical properties of developed nanocomposites and also help to enhance the interfacial bond between reinforcement and matrix materials $[43,44]$. 
The high resolution transmission electron microscope (TEM) was performed to analyze the micrographic view of $\mathrm{TiO}_{2}$ nanoparticles shown in Fig. 4(a). It was observed that, the nano ceramic particle forms dense aggregates made by crystallites whose sizes were varied from 10 to 20 nano meter. The Fig. 4(b) showed the selected area electron diffraction (SAED) ring pattern with the mark of Miller indices of $\mathrm{TiO}_{2}$ nanoparticles. The SAED is the crystallographic experimental methods to examine crystal structure pattern of $\mathrm{TiO}_{2}$ nanoparticles [25]. The ring pattern of $\mathrm{TiO}_{2}$ nanoparticles confirmed that the granular appearances of ring are well balanced with polycrystalline in nature where sizes of the ingredient crystallites ranged between 10 to $20 \mathrm{~nm}$.

\subsection{Characterization of composite laminates}

\subsubsection{Tensile properties}

For the design and development of new composite materials, it is very essential to identify the tensile properties. To find out the tensile strength, tensile modulus and elongation at break of the developed composites, tensile testing has been performed. The maximum tensile strength identifies the ability of a material to resist failure, whereas, the ability of the material to resist deformation or plastic deformation characterized by tensile modulus also called as stiffness of the materials and elongation at break identifies the ability of elongation of the material before it goes through fracture and failure [45]. Fig. 5(a) showed the typical engineering stress-strain graph and Fig. 5(b) showed the comparative analysis of tensile properties with influence of different weight fraction of $\mathrm{TiO}_{2}$ nanoparticles for developed composite laminates.

The addition of $\mathrm{TiO}_{2}$ nanoparticles up to certain percentages along with glass fiber showed an increment in tensile strength and tensile modulus for developed composites. This may be due to the addition of fine and well dispersion of nanoparticles along with glass fibers that improve the interfacial bonding strength between matrix and fiber. The better interfacial bonding helps to transmit higher load and stress from matrix to reinforced materials [30]. Form the results, it observed that, the tensile strength of the developed composites was recorded maximum for GFRP-T1.0 (341.53 MPa) which was 38.56\% higher than GFRP-T0.0. Furthermore, the tensile modulus was recorded highest for GFRP-T1.5 (12.89 GPa) which was 52.72\% greater than the GFRP-T0.0 composite laminates due to rigidity and stiffness provided by the nanoparticles. Further increments of nanoparticles loading (More than 1.5\%) showed, decrement in tensile properties due to agglomeration/clustering effects of $\mathrm{TiO}_{2}$ nanoparticles with epoxy 
matrix while, presence of excessive nanoparticles in developed composites may also obstacles the matrix continuity, which may result the decrements in tensile properties $[8,30]$.

\subsubsection{Flexural properties}

To find the flexural properties of developed composite laminates such as flexural strength, flexural modulus and maximum deflection, the three-point bending test has been performed. Fig. 6(a) showed the flexural stress-strain plot and Fig. 6(b) showed the comparative analysis of flexural properties with influence of different weight fraction of $\mathrm{TiO}_{2}$ nanoparticles for developed composite laminates. As similar to tensile properties, the addition of $\mathrm{TiO}_{2}$ nanoparticles up to $1 \%$ by weight along with glass fiber showed an increment in flexural strength while maximum flexural modulus was recorded for GFRP-T1.5 composite laminates. The maximum flexural strength was observed for the GFRP-T1.0 (421.26 MPa) which was 30.52\% greater than GFRP-T0.0 composite laminates. This increment may be due to dispersion of $\mathrm{TiO}_{2}$ surface area and the adhesive bond between matrix and reinforcement at lower weight of $\mathrm{TiO}_{2}$ nanoparticles. The maximum flexural modulus was observed for GFRP-T1.5 (16.19 GPa) which was $34.13 \%$ greater than GFRP-T0.0 composite laminates. This increment happened due to greater adhesion bond between fiber and matrix with fine dispersion of $\mathrm{TiO}_{2}$ nanoparticles while orientation of fibers also enhanced and affects the properties of developed composite laminates [46]. But at higher weight fraction of nanoparticles loading created agglomeration/clustering effects which results in a sudden decrement in the mechanical properties [8, 47].

\subsubsection{Micro-hardness}

The ability to resist localized plastic deformation of any material is known as hardness of the material [48]. Fig. 7 showed the micro hardness of developed composite laminates and recorded highest micro hardness of $36.42 \mathrm{Hv}$ for GFRP-T1.0 composites which was $48.53 \%$ higher than GFRP-T0.0 composite laminates. From result, it was notified that, the addition of $\mathrm{TiO}_{2}$ nanoparticles from $0.5 \%$ to $1 \%$ increased the micro hardness of developed composites. This increment at lower weight fraction may be attributed to greater interfacial bond of matrix-fiber with dispersion of $\mathrm{TiO}_{2}$ nanoparticles. But further increment of nanoparticles weight fraction ( $1.5 \%$ to $2 \%)$, the continuously decrements in micro hardness values were recorded. This may be due to the agglomeration/clusterization of nanoparticles at higher weight fraction [49].

\subsubsection{Impact strength}


To identify the shock and energy absorption ability of developed composite laminates, Charpy impact testing has been performed. Fig. 7 represented the impact strength of different developed composite laminates. From the test result, it was observed that, the addition of $\mathrm{TiO}_{2}$ nanoparticles (up to $1 \%$ ) along with glass fiber reinforcements showed increment in impact strength while, further increment of $\mathrm{TiO}_{2}$ nanoparticles weight fraction (more than $1 \mathrm{wt} \%$ ) observed decrement in impact strength. The better dispersion of nanoparticles in GFRP composite laminates helps to make better interfacial bonding between reinforcing material and matrix materials that showed increment in impact strength at a lower weight fraction of nanoparticles. But excessive addition of nanoparticles (more than $1 \mathrm{wt} \%$ ) in developed composite laminates make it more brittle and that evidence of brittleness revealed reduction in impact strength values as well as reduction in elongation before break value for tensile and flexural specimen composite laminates [50]. The maximum impact strength was recorded for the GFRP-T1.0 $\left(27.43 \mathrm{KJ} / \mathrm{m}^{2}\right)$ which was $327.10 \%$ more than GFRP-T0.0 composite laminates.

\subsubsection{Inter-laminar shear strength (ILSS)}

One of the major failure criteria of composite laminates are investigated when load is subjected to transverse direction and these failures are analyzed due to inter-laminar shear stress. So, for the design and development process of laminated composites, it is very imported to investigate the ILSS. To examine the ILSS properties of developed composites, short beam shear testing has been performed. Fig. 7 represented the result of the inter-laminar shear test and maximum interlaminar strength was observed for GFRP-T1.0 (39.44 MPa) which was $25.22 \%$ greater than GFRP-T0.0 composite laminates. The addition of $\mathrm{TiO}_{2}$ nanoparticles with glass fiber reinforcement results better interfacial bond with better dispersion of nanoparticles that improved the ILSS of developed composites. This might be happened due to strong shear strength between laminates up to $1 \%$ loading of $\mathrm{TiO}_{2}$ nanoparticles while, further increments of nanoparticles loading, the decrements was recorded in inter-laminar bonding strength due to high brittleness and agglomeration of the nanoparticles [51].

\subsubsection{Fracture properties}

The fracture toughness and fracture energy of developed composite laminates have been investigated and represented in Fig. 8. Due to the presence of a high cross-link structure in epoxy polymer, the polymer showed brittle in nature and low fracture toughness value $\left(0.58 \mathrm{MPa}-\mathrm{m}^{1 / 2}\right)$. The addition of glass fiber with epoxy matrix increased the toughness value up to $3.35 \mathrm{MPa}-\mathrm{m}^{1 / 2}$. 
This increment suggests that the addition of fiber made the material ductile in nature. Now the addition of $\mathrm{TiO}_{2}$ nanoparticles with glass fiber composite showed further increment in toughness value. The maximum toughness and fracture energy values of $3.92 \mathrm{MPa}-\mathrm{m}^{1 / 2}$ and $5.86 \mathrm{KJ} / \mathrm{m}^{2}$ respectively were recorded for GFRP-T1.0 composite which was $17.01 \%$ and $40.19 \%$ higher than GFRP-T-0.0 composite laminates respectively. But further addition of nanoparticles (more than $1 \%$ ) showed decrement in toughness and fracture energy values. The increments in fracture properties are analyzed due to crack path deflection, crack pining and plastic void growth where dispersion of nanoparticles creates Vander wall bond between molecular chains of epoxy and $\mathrm{TiO}_{2}$ nanoparticles that leads to enhance constrained between nanoparticles/polymer chain and polymer chain itself [52].

At low weight fraction, the nanoparticles interrupted the crack front propagation inside the composite laminates. These nanoparticles create obstacles at the crack front and result in crack front bowing in the middle of nanoparticles. This may lead to creating secondary crack which results in increments of fracture toughness and fracture energy [44]. But for higher weight fraction of $\mathrm{TiO}_{2}$ nanoparticles, the bonding strength decreased rapidly due to agglomeration of nanoparticles that reduce the homogeneity and effective weight fraction of nanoparticles. Therefore, debonding of the nanoparticles with epoxy polymer chain reduces that creates the cavity and hence, lower fracture toughness and fracture energy are recorded at higher weight fraction of $\mathrm{TiO}_{2}$ nanoparticles [53].

\subsection{Thermal stability of composite laminates}

To identify the thermal stability of the developed composites, thermo gravimetric analysis has been performed. Fig. 9 showed the thermo grams of the composite laminates. From obtained results, it was observed that the mass loss of the composites has occurred in three stages. The first stage was recorded at $450^{\circ} \mathrm{C}$, second was at $550^{\circ} \mathrm{C}$ and the third stage was up to $650^{\circ} \mathrm{C}$. The degradation of mass at each stage has been tabulated in Table 1. From results, it was analyzed that, the addition of $\mathrm{TiO}_{2}$ nanoparticles increased the thermal stability of the developed composite laminates. This may be happened due to the catalytic effect of $\mathrm{TiO}_{2}$ nanoparticles with cross-link nature epoxy polymer where the cross link density results to improve the decomposition temperature of the developed composites [54].

At low $\mathrm{TiO}_{2}$ nanoparticles loading the thermal degradation were high and low residual mass at $900^{\circ} \mathrm{C}$ was analyzed for developed composite laminates. The residual of $44.64 \%$ for 
GFRP-T0.0 composite was recorded that followed by GFRP-T0.5< GFRP-T1.0< GFRP-T1.5< GFRP-T2.0 composite laminates where the residual mass of $48.31 \%, 53.41 \%, 55.36 \%$ and $57.23 \%$ are observed. Therefore, it revealed that, as the weight fraction of $\mathrm{TiO}_{2}$ nanoparticles increases, the percentage of residual mass also increases due to the ceramic nature of $\mathrm{TiO}_{2}$ nanoparticles. These nanoparticles created a barrier to oxygen and heat inside the epoxy matrix that results the better thermal stability for developed composite laminates [55].

\subsection{Glass transition temperature $\left(T_{g}\right)$}

To investigate the glass transition temperature of developed composite, differential thermal analysis (DTA) has been performed. The DTA measured the temperature difference between the specimens and the reference materials. When the heating began, change in temperature $(\Delta \mathrm{T})$ was measured with differential thermocouple until the static state was reached [56]. The measured $\Delta \mathrm{T}$ is also known as glass transition temperature $\left(\mathrm{T}_{\mathrm{g}}\right)$ of the materials. Fig. 10(a) showed the DTA curve with $\mathrm{T}_{\mathrm{g}}$ value and observed that, as the weight fraction of $\mathrm{TiO}_{2}$ nanoparticles increased, the $\mathrm{T}_{\mathrm{g}}$ of the developed composite was also increased (up to $1.5 \%$ of $\mathrm{TiO}_{2}$ loading), moreover, there is a sudden drop was observed for $2 \%$ nanoparticles loading. The comparative $\mathrm{T}_{\mathrm{g}}$ value at different weight fraction of $\mathrm{TiO}_{2}$ nanoparticles are represent in Fig. 10(b). The maximum $\mathrm{T}_{\mathrm{g}}$ was observed for GFRP-T1.5 $\left(116^{\circ} \mathrm{C}\right)$ which was $20.83 \%$ greater than GFRP-T0.0 composite laminates. For thermosetting polymer (epoxy resin) based composites, factors likemolecular weight, cross-link density, fiber/filler- matrix interfacial bonding and polymer tactility played a vital role to identify the $\mathrm{T}_{\mathrm{g}}$ value of the composites [57]. In the present study, addition of nanoparticles (up to lower weight fraction, 1.5\%) along with glass fiber increased the interfacial interaction between matrix and reinforcing material where the dispersion of $\mathrm{TiO}_{2}$ nanoparticles played vital role for increments in thermal stability and glass transition temperature. However, at higher weight fraction of nanoparticles, clusterization and agglomeration effect has been observed, which reduced the cross link density of epoxy matrix and interfacial interaction between matrix and reinforcing material [58]. Therefore, the glass transition temperature for GFRP-T2.0 decreased rapidly.

\subsection{Surface morphology and failure mechanism}

The surface microstructure and fracture behavior of developed composite laminates are characterized with help of scanning electron microscopy (SEM). The morphology analysis was examined with high magnification of $100 \mathrm{x}$ to $5000 \mathrm{x}$ and voltage of $5 \mathrm{kV}$ at atmospheric 
temperature. The dispersion of $\mathrm{TiO}_{2}$ nanoparticles with epoxy matrix and stacking sequence of glass fiber were analyzed and showed in Fig. 11. The different types of failure such as brittle fracture of epoxy matrix, fiber breakage, debonding, pullout, crushing and delamination of developed composites under tensile and flexural testing were also analyzed on the fracture surfaces. The results examined that, dispersion of $\mathrm{TiO}_{2}$ nanoparticles in epoxy matrix are properly mixed with less than one $\%$ of voids that, results superior interfacial bond with glass fiber reinforcements. The similar observation is also reported with previous studies [59, 60]. The thermo-mechanical performances of developed composites indicated that, incorporation of $\mathrm{TiO}_{2}$ nanoparticles up to $1.5 \% \mathrm{TiO}_{2}$ nanoparticles are well dispersed with epoxy matrix and create strong interfacial bond with glass fibers. The glass fiber can be transferred their high reinforcing potential to $\mathrm{TiO}_{2}$ nanoparticles and matrix materials that revealed high mechanical and thermal properties with less fiber breakage and pullout [25]. Whereas, the presence of excess amount of nanoparticles showed visible clusterization and agglomerate with epoxy matrix. The effects of clustering/agglomeration act as the stress concentration sites on the developed composite due to generation of cavitations, void, debonding, and cracks with epoxy matrix and finally, affect the performances of composite materials [25, 38]. Thus, further increments of $\mathrm{TiO}_{2}$ nanoparticles loading (more than 1.5\%) showed improper bonding with epoxy matrix and reduction in their mechanical and thermal performances were recorded for developed composite laminates. The current developed composite laminates are mostly failed due to brittle fracture of epoxy resin with linear behavior of stress-strain curve up to failure and there in no plastic deformation occurred.

\section{Conclusion}

Nanoparticles are gaining too much attention to embedded with glass fiber reinforced epoxy composites due to their advanced physical and structure properties. In this study, the effective role of $\mathrm{TiO}_{2}$ nanoparticles has been demonstrated towards fabrication of superior physical, mechanical and thermal properties based on epoxy glass fiber composites. The $\mathrm{TiO}_{2}$ nanoparticles are prepared with sol-gel methods and mix in epoxy matrix with help of mechanical starring and sonication to ensure better dispersion. Then, vacuum assisted resin infusion molding techniques (VARIM) are used to fabricate the composite laminates with reinforcements of glass fibers. The effects of different weight fraction $(0.5 \%, 1.0 \%, 1.5 \%$, and $2.0 \%$ ) of $\mathrm{TiO}_{2}$ nanoparticles on glass fiber reinforced epoxy composites are studied and compare 
the thermo-mechanical properties with glass fiber reinforced composites (GFRP-T0.0). Based on the characterization, the following conclusions are drawn.

- The physical and chemical characterization of derived $\mathrm{TiO}_{2}$ nanoparticles with $\mathrm{XRD}$ and FTIR confirmed better structure and functional properties to enhance the dispersion qualities with matrix and proved that, the dispersion of nanoparticles to be very efficient to make better interfacial bond with epoxy matrix that reduce the voids and defaults in developed composites.

- The physical and chemical absorption of water contents were analyzed with TGA/DTG and percentage weight loss and weight loss rate were recorded. The physical absorbed water evaporated at $120^{\circ} \mathrm{C}$ with $13.8 \%$ of water contents that made weak bond with $\mathrm{TiO}_{2}$ while, chemical absorption of water made strong bond with $\mathrm{TiO}_{2}$ at $300^{\circ} \mathrm{C}$ with $9.88 \%$ of water contents.

- The surface morphology and microstructure of $\mathrm{TiO}_{2}$ nanoparticles were characterized by TEM and FESEM and showed better crystallographic structure with spherical in shape to improve the thermo-mechanical properties of developed composite laminates.

- The developed composite laminates were used to perform tensile, flexural, impact, interlaminar shear, micro-hardness, and fracture tests and observed that, the inclusion of $\mathrm{TiO}_{2}$ nanoparticles up to $1.0 \%$ with glass fiber epoxy composites (GFRP-T1.0) enhanced their tensile, flexural, ILSS and impact strength while tensile and flexural modulus were recorded maximum for GFRP-T1.5 due to high stiffness and rigidity provided by $\mathrm{TiO}_{2}$ nanoparticles.

- The highest micro-hardness $(36.42 \mathrm{Hv})$, fracture toughness $\left(3.92 \mathrm{MPa}-\mathrm{m}^{0.5}\right)$ and fracture energy $\left(5.86 \mathrm{KJ} / \mathrm{m}^{2}\right)$ exhibited for GFRP-T1.0 composite laminates while, further increments of nanoparticles loading agglomerate with epoxy matrix that increased the brittleness of materials and reduction in thermo-mechanical properties were recorded.

- The maximum thermal stability and decomposition of developed composites are characterized where the degradation temperature starts to $450^{\circ} \mathrm{C}$ and degraded at $650^{\circ} \mathrm{C}$. The maximum glass transition temperature $\left(\mathrm{T}_{\mathrm{g}}\right)$ of $116^{\circ} \mathrm{C}$ for GFRP-T1.5 composites were recorded due to mobility loss of cross link density of epoxy with interaction of $\mathrm{TiO}_{2}$ nanoparticles.

- The morphology analysis at fracture surfaces was characterized by SEM and failure of developed composites were analyzed with fiber breakage, fiber pullout, fiber/nanoparticles 
debonding, cracking of epoxy matrix with brittle fracture. The excess presence of nanoparticles showed agglomeration and clusterization due to cavitations and debris formed with epoxy matrix.

The effective results and investigations conclude that, the improvement of thermo-mechanical properties due to principal of toughening mechanism may have interesting for various industrial applications.

\section{Declaration of conflicting interest}

The authors declare that there are no potential conflicts towards financial interest for investigation, authorship, and/or publication of this study.

Funding: The authors do not receive any financial supports from any organization to carry out the present research work. .

\section{References}

1. Pinto D, Bernardo L, Amaro A, Lopes S. Mechanical properties of epoxy nanocomposites using titanium dioxide as reinforcement-a review. Constr Build Mater 2015, 95:506-24.

2. Schutz RJ, Gaul RW, Murray MA. Guide for the selection of polymer adhesives with concrete. ACI Mater J 1992, 89:90-105.

3. Uomoto T, Mutsuyoshi H, Katsuki F, Misra S. Use of fiber reinforced polymer composites as reinforcing material for concrete. J Mater Civ Eng 2002, 14:191-209.

4. Varga C, Miskolczi N, Bartha L, Lipóczi G. Improving the mechanical properties of glassfibre-reinforced polyester composites by modification of fibre surface. Mater Des 2010, 31:185-93.

5. El-Tantawy F, Kamada K, Ohnabe H. In situ network structure, electrical and thermal properties of conductive epoxy resin-carbon black composites for electrical heater applications. Mater Lett 2002, 56:112-26.

6. El-Tantawy F, Kamada K, Ohnabe H. A novel way of enhancing the electrical and thermal stability of conductive epoxy resin-carbon black composites via the Joule heating effect for heating-element applications. J appl polym sci 2003, 87:97-109.

7. Seshanandan G, Ravindran D, Sornakumar T. Mechanical properties of nano titanium oxide particles-hybrid jute-glass FRP composites. Mater Today: Proceedings 2016, 3:1383-8.

8. Nguyen VG, Thai H, Mai DH, Tran HT, Vu MT. Effect of titanium dioxide on the properties of polyethylene/TiO2 nanocomposites. Compos B: Eng 2013, 45:1192-8. 
9. Kumar K, Ghosh PK, Kumar A. Improving mechanical and thermal properties of TiO2epoxy nanocomposite. Compos B: Eng 2016, 97:353-60.

10. De B, Voit B, Karak N. Transparent luminescent hyperbranched epoxy/carbon oxide dot nanocomposites with outstanding toughness and ductility. ACS Appl Mater Interfaces 2013, 5:10027-34.

11. Khare KS, Khare R. Effect of carbon nanotube dispersion on glass transition in cross-linked epoxy-carbon nanotube nanocomposites: role of interfacial interactions. $J$ Phys Chem B 2013, 117:7444-54.

12. Wang K, Chen L, Wu J, Toh ML, He C, Yee AF. Epoxy nanocomposites with highly exfoliated clay: mechanical properties and fracture mechanisms. Macromolecules 2005, 38(3):788-800.

13. Eksik O, Gao J, Shojaee SA, Thomas A, Chow P, Bartolucci SF, et al. Epoxy nanocomposites with two-dimensional transition metal dichalcogenide additives. Acs Nano 2014, 8:5282-9.

14. Pati MK, Pattojoshi P, Roy GS. Fabrication and characterization of graphene based nanocomposite for electrical properties. Adv Mater Phys Chem 2015, 5:22-30.

15. Singh RP, Zhang M, Chan D. Toughening of a brittle thermosetting polymer: effects of reinforcement particle size and volume fraction. J mater sci 2002, 37:781-8.

16. Tong Y, Li Y, Xie F, Ding M. Preparation and characteristics of polyimide-TiO2 nanocomposite film. Polym int 2000, 49:1543-7.

17. Džunuzović E, Vodnik V, Jeremić K, Nedeljković JM. Thermal properties of PS/TiO2 nanocomposites obtained by in situ bulk radical polymerization of styrene. Mater Lett 2009, 63:908-10.

18. Yamashita H, Harada M, Misaka J, Takeuchi M, Neppolian B, Anpo M. Photocatalytic degradation of organic compounds diluted in water using visible light-responsive metal ionimplanted TiO2 catalysts: Fe ion-implanted TiO2. Catal Today 2003, 84:191-6.

19. Polizos G, Tuncer E, Sauers I, More KL. Physical properties of epoxy resin/titanium dioxide nanocomposites. Polym Eng Sci 2011, 51:87-93.

20. Zewde B, Pitliya P, Raghavan D. The role of surface modified TiO 2 nanoparticles on the mechanical and thermal properties of CTBN toughened epoxy nanocomposite. J Mater Sci 2016, 51:9314-29. 
21. Bagheri AR, Ghaedi M, Asfaram A, Jannesar R, Goudarzi A. Design and construction of nanoscale material for ultrasonic assisted adsorption of dyes: application of derivative spectrophotometry and experimental design methodology. Ultrason sonochem 2017, 35:11223.

22. Zhou Y, White E, Hosur M, Jeelani S. Effect of particle size and weight fraction on the flexural strength and failure mode of $\mathrm{TiO} 2$ particles reinforced epoxy. Mater Lett 2010, 64:806-9.

23. Hamad A, Turaif A. Effect of nano TiO2 particle size on mechanical properties of cured epoxy resin. J. Prog Org Coat 2010, 69:241-6.

24. Chatterjee A, Islam MS. Fabrication and characterization of TiO2-epoxy nanocomposite. Mater Sci Eng A 2008, 487:574-85.

25. Zahrouni A, Bendaoued A, Salhi R. Effect of sol-gel derived TiO2 nanopowders on the mechanical and structural properties of a polymer matrix nanocomposites developed by vacuum-assisted resin transfer molding (VARTM). Ceram Int 2021, 47:9755-62.

26. Nayak RK, Ray BC. Water absorption, residual mechanical and thermal properties of hydrothermally conditioned nano- $\mathrm{Al}_{2} \mathrm{O}_{3}$ enhanced glass fiber reinforced polymer composites. Polym Bull 2017, 74:4175-94.

27. Karnati SR, Agbo P, Zhang L. Applications of silica nanoparticles in glass/carbon fiberreinforced epoxy nanocomposite. Compos Commun 2020, 17:32-41.

28. Wetchakun N, Incessungvorn B, Wetchakun K, Phanichphant S. Influence of calcination temperature on anatase to rutile phase transformation in $\mathrm{TiO} 2$ nanoparticles synthesized by the modified sol-gel method. Mater Lett 2012, 82:195-8.

29. Bazrgari D, Moztarzadeh F, Sabbagh-Alvani AA, Rasoulianboroujeni M, Tahriri M, Tayebi L. Mechanical properties and tribological performance of epoxy/Al2O3 nanocomposite. Ceram Int 2018, 44:1220-4.

30. Goyat MS, Ghosh PK. Impact of ultrasonic assisted triangular lattice like arranged dispersion of nanoparticles on physical and mechanical properties of epoxy-TiO2 nanocomposites. Ultrason sonochem 2018, 42:141-54.

31. ASTM Standard D638, Standard Test Method for Tensile Properties of Plastics, ASTM International, West Conshohocken, PA, 2010 
32. ASTM Standard D790, Standard Test Methods for Flexural Properties of Unreinforced and Reinforced Plastics and Electrical Insulating Materials, ASTM International, West Conshohocken, PA, 2010.

33. ASTM E384-99, Standard Test Method for Microindentation Hardness of Materials, ASTM International, West Conshohocken, PA, 1999.

34. ASTM D 256, Standard test methods for determining the Izod pendulum impact resistance of plastics. American Society for Testing Materials 2000.

35. ASTM D2344/ D2344M standard. Apparent interlaminar shear strength of unidirectional parallel fiber composites by short beam method; 2000.

36. ASTM Standard D5045-14, Standard Test Methods for Plane-Strain Fracture Toughness and Strain Energy Release Rate of Plastic Materials" Annual Book of ASTM Standards, Part, 8 2014.

37. Wang CL, Hwang WS, Chu HL, Lin HJ, Ko HH, Wang MC. Kinetics of anatase transition to rutile $\mathrm{TiO} 2$ from titanium dioxide precursor powders synthesized by a sol-gel process. Ceram Int 2016, 42:13136-43.

38. Sahnesarayi MK, Sarpoolaky H, Rastegari S. Effect of heat treatment temperature on the performance of nano-TiO2 coating in protecting 316 stainless steel against corrosion under UV illumination and dark conditions. Surf Coat Technol 2014, 258:861-70.

39. Iftikhar S, Warsi MF, Haider S, Musaddiq S, Shakir I, Shahid M. The impact of carbon nanotubes on the optical, electrical, and magnetic parameters of Ni2+ and $\mathrm{Co} 2+$ based spinel ferrites. Ceram Int 2019, 45:21150-61.

40. Parale VG, Kim T, Lee KY, Phadtare VD, Dhavale RP, Park HH. Hydrophobic TiO2-SiO2 composite aerogels synthesized via in situ epoxy-ring opening polymerization and sol-gel process for enhanced degradation activity. Ceram Int 2020, 46:4939-46.

41. Salhi R, Deschanvres JL. Efficient green and red up-conversion emissions in Er/Yb co-doped TiO2 nanopowders prepared by hydrothermal-assisted sol-gel process. J Lumin 2016, 176:250-9.

42. Liu N, Guo X, Navrotsky A, Shi L, Wu D. Thermodynamic complexity of sulfated zirconia catalysts. J Catal 2016, 342:158-63. 
43. Parale VG, Kim T, Phadtare VD, Yadav HM, Park HH. Enhanced photocatalytic activity of a mesoporous $\mathrm{TiO} 2$ aerogel decorated onto three-dimensional carbon foam. J mol liq 2019, 277:424-33.

44. Saha A, Kumar S, Kumar A. Influence of pineapple leaf particulate on mechanical, thermal and biodegradation characteristics of pineapple leaf fiber reinforced polymer composite. $J$ Polym Res 2021, 28:1-23.

45. Rahman R, Putra SZ. Tensile properties of natural and synthetic fiber-reinforced polymer composites. Mechanical and physical testing of biocomposites, fibre-reinforced composites and hybrid composites. Woodhead Publishing Series Compos Sci Eng 2019, 81-102.

46. Kinloch AJ, Masania K, Taylor AC, Sprenger S, Egan D. The fracture of glass-fibrereinforced epoxy composites using nanoparticle-modified matrices. J Mater Sci 2008, 43:1151-4.

47. Sudheer M, Prabhu R, Raju K, Bhat T. Effect of filler content on the performance of epoxy/PTW composites. Adv Mater Sci Eng 2014, 2014:1-11.

48. Yanikoglu N, Duymus ZY, Yilmaz B. Effects of different solutions on the surface hardness of composite resin materials. Dental mater j 2009, 28:344-51.

49. Rao V, Singh PK, Dwivedi DK. Effect of third element on thermo-mechanical properties of Se-Te-M ( $\mathrm{M}=\mathrm{Ge}, \mathrm{Sb})$ glassy alloys: A comparatively study. InAIP Conference Proceedings 2020 2220:120002 AIP Publishing LLC.

50. Rostamiyan Y, Fereidoon A, Mashhadzadeh AH, Ashtiyani MR, Salmankhani A. Using response surface methodology for modeling and optimizing tensile and impact strength properties of fiber orientated quaternary hybrid nano composite. Compos B: Eng 2015, 69:304-16.

51. Zaer-Miri S, Khosravi H. Assessment of the wear behavior and interlaminar shear properties of modified nano-TiO2/jute fiber/epoxy multiscale composites. J Ind Text 2019;0:1-16.

52. Singh SK, Singh S, Kumar A, Jain A. Thermo-mechanical behavior of TiO2 dispersed epoxy composites. Eng Fract Mech 2017, 184:241-8.

53. Fu SY, Mai YW, Lauke B, Yue CY. Synergistic effect on the fracture toughness of hybrid short glass fiber and short carbon fiber reinforced polypropylene composites. Mater Sci Eng C 2002, 323:326-35. 
54. Mahfuz H, Rangari VK, Islam MS, Jeelani S. Fabrication, synthesis and mechanical characterization of nanoparticles infused polyurethane foams. Compos Part A: Appl Sci Manuf 2004, 35:453-60.

55. Xiong L, Liang HB, Wang RM, Pang Y. The effect of surface modification of TiO2 with diblock copolymers on the properties of epoxy nanocomposites. Polym Plast Tech Eng 2010, 49:1483-8.

56. Trache D, Maggi F, Palmucci I, DeLuca LT. Thermal behavior and decomposition kinetics of composite solid propellants in the presence of amide burning rate suppressants. $J$ Therm Anal Calorim 2018, 132:1601-15.

57. Sun Y, Zhang Z, Moon KS, Wong CP. Glass transition and relaxation behavior of epoxy nanocomposites. J. Polym. Sci. Part B Polym Phys 2004, 42:3849-3858.

58. Wetzel B, Rosso P, Haupert F, Friedrich K. Epoxy nanocomposites-fracture and toughening mechanisms. Eng Fract Mech 2006, 73:2375-98.

59. Saberian MH, Ashenai Ghasemi F, Ghasemi I, Bagheri MS. Morphology, mechanical behavior, and prediction of A-glass/SiO2/epoxy nanocomposite using response surface methodology. J Elastomers Plast 2019, 51:669-83.

60. Nayak RK, Ray BC. Influence of seawater absorption on retention of mechanical properties of nano-TiO 2 embedded glass fiber reinforced epoxy polymer matrix composites. Arch Civ Mech Eng 2018, 18:1597-607. 


\section{Figures}

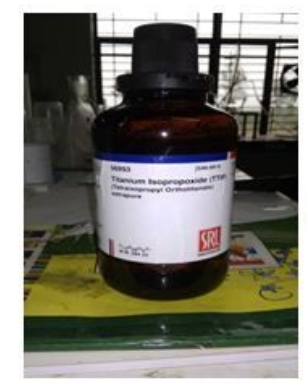

Titanium Isopropoxide

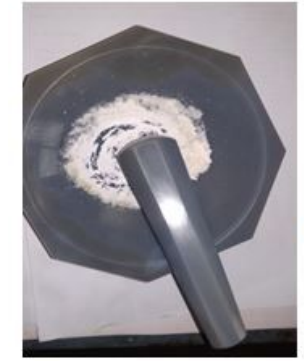

Prepared $\mathrm{TiO}_{2}$ nanoparticles

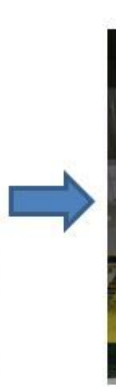

Isopropanol

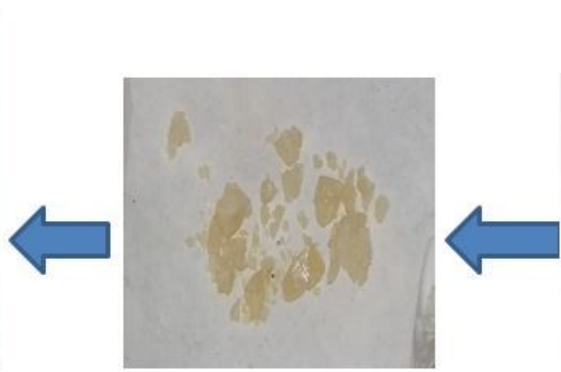

Yellow-white coarse $\mathrm{TiO}_{2}$ is obtained

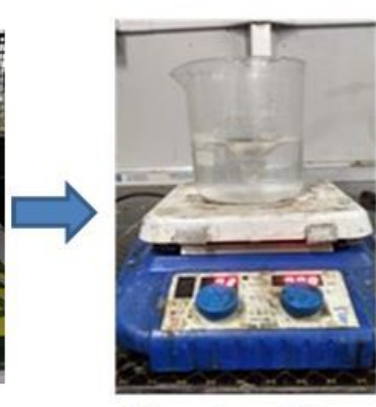

DI water at $70^{\circ} \mathrm{C}$ stirring at $700 \mathrm{rpm}$

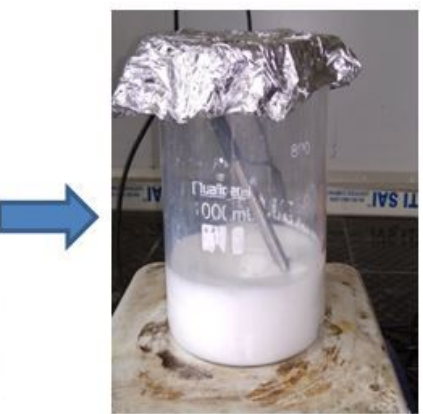

Gel formation started under vigorous stirring

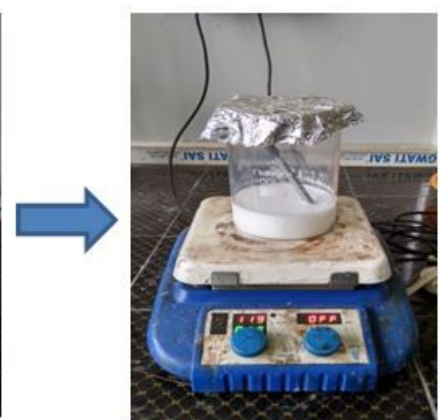

Volume of solution decreases to half of the solutions

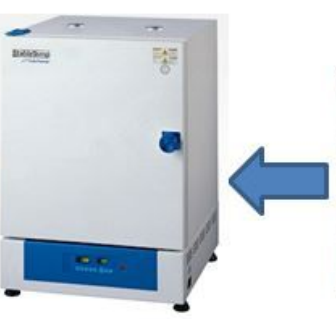

Drying in oven at $100^{\circ} \mathrm{C}$ for 3 hours

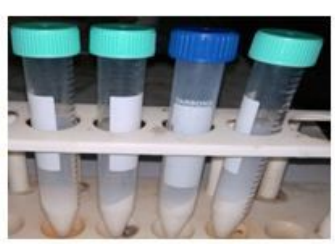

Centrifuge tube with filtered $\mathrm{TiO}_{2}$

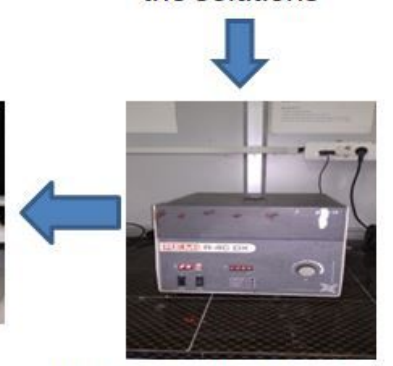

Washed with ethanol in bench top centrifuge

\section{Figure 1}

Preparation of TiO2 nanoparticles with sol-gel method

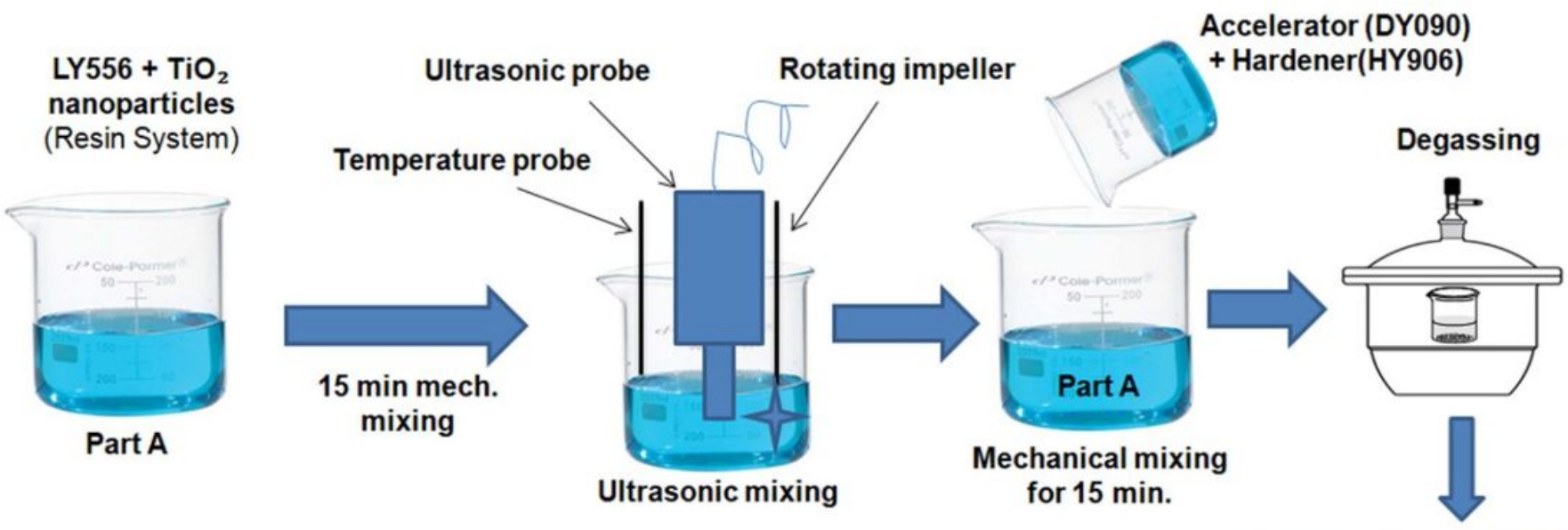

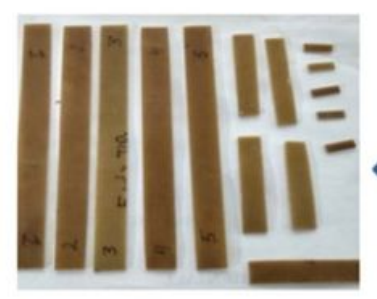

Prepared samples with ASTM

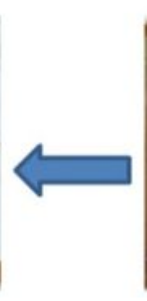

\section{Prepared composite} laminates
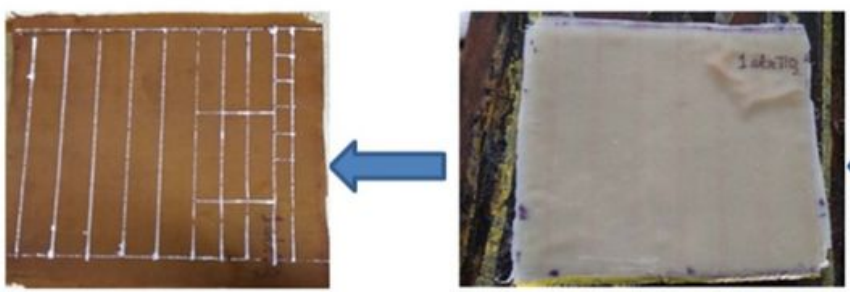

Pre-curing at $120^{\circ} \mathrm{C}$ for $2 \mathrm{~h}$ and post-curing at $160^{\circ} \mathrm{C}$ for $6 \mathrm{~h}$

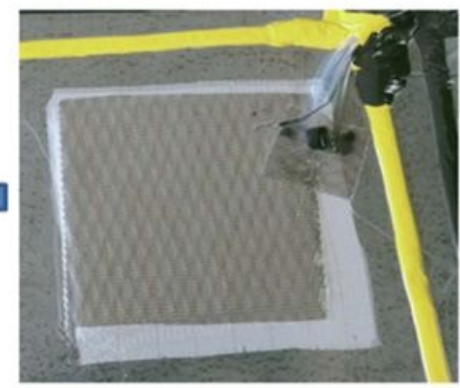

VARIM process 
Figure 2

Fabrication processes of GFRP composite laminates

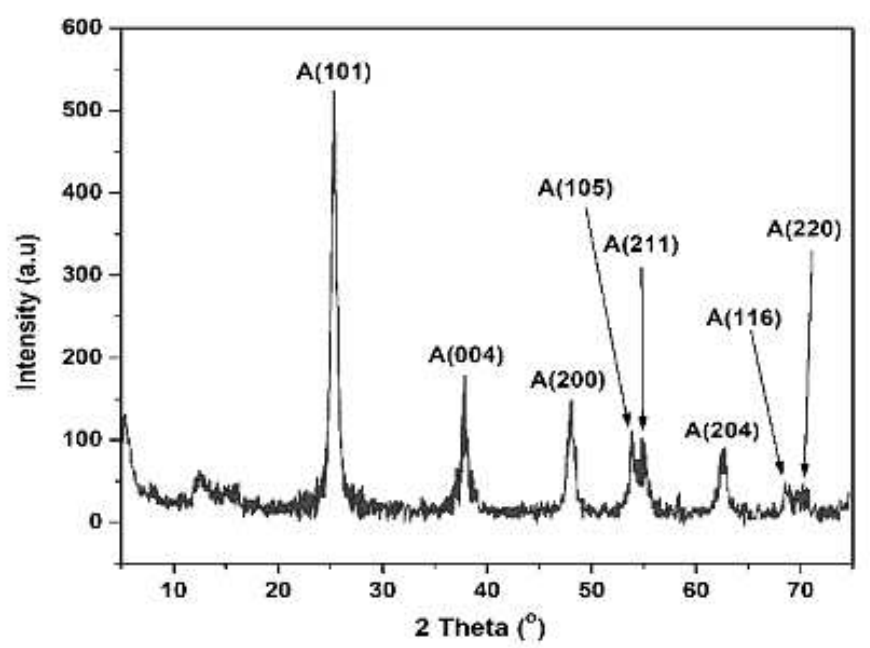

(a)

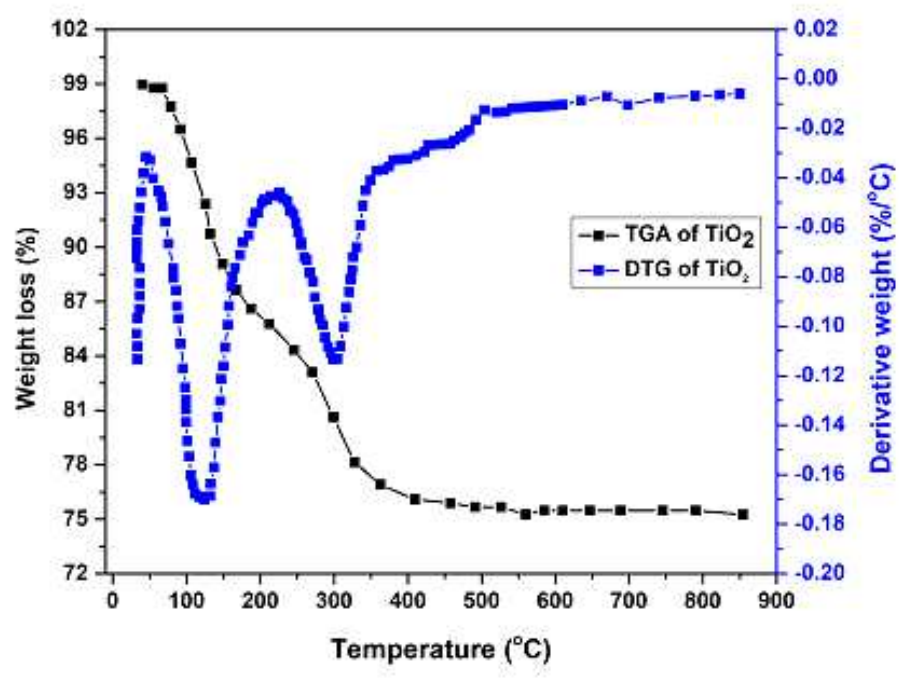

(c)

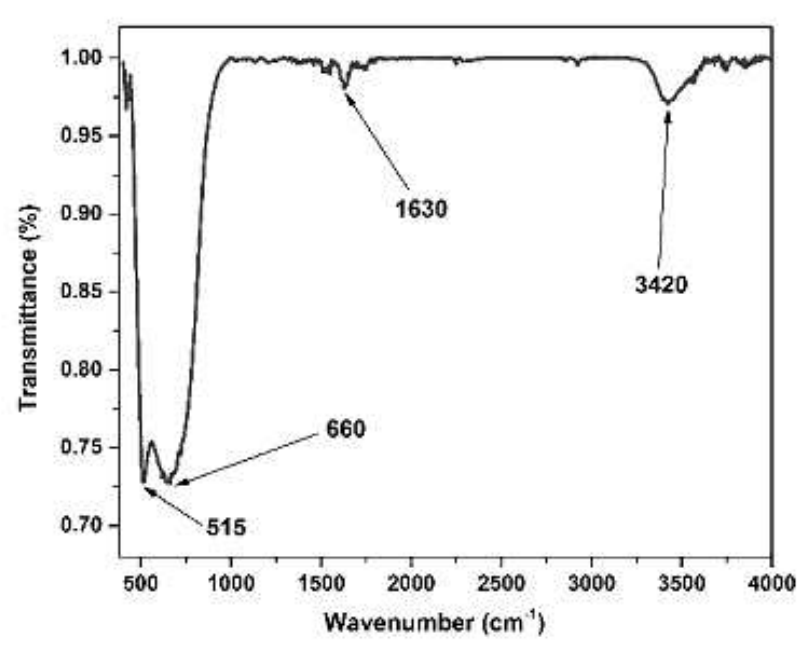

(b)

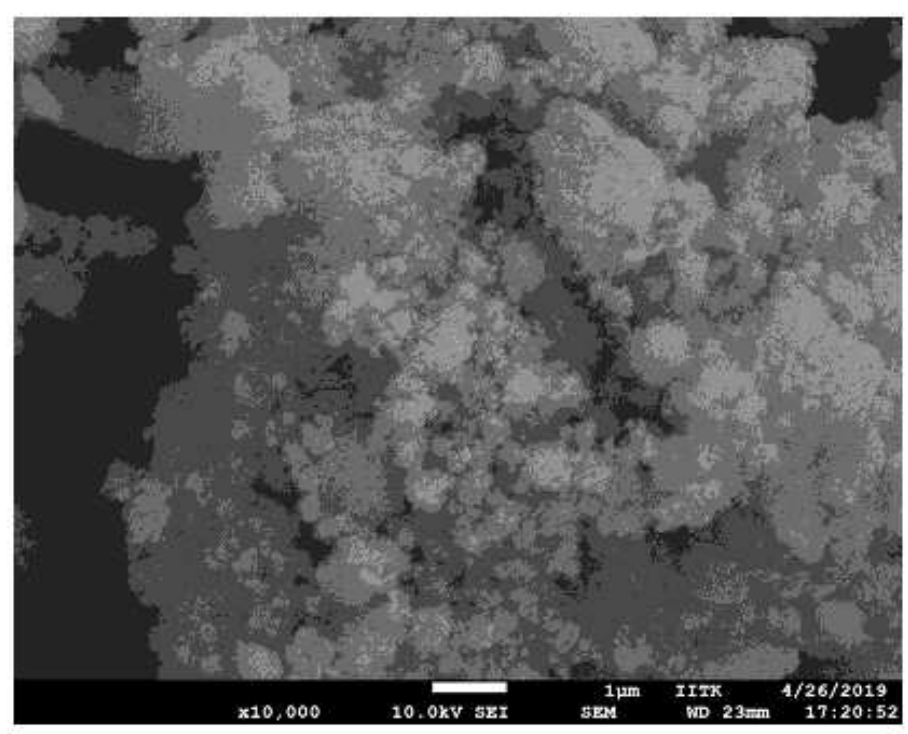

(d)

\section{Figure 3}

(a) XRD pattern, (b) FTIR spectra, (c) TGA and DTG, (d) FESEM morphology of TiO2 nanoparticles 


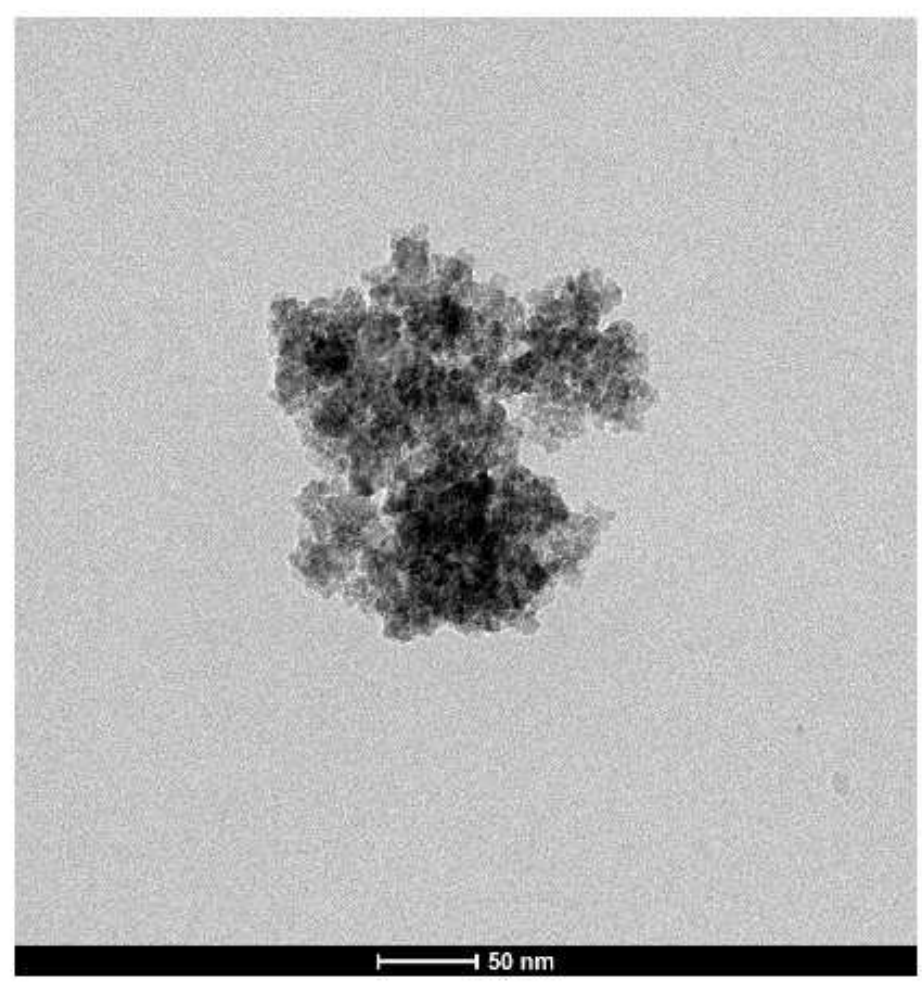

(a)

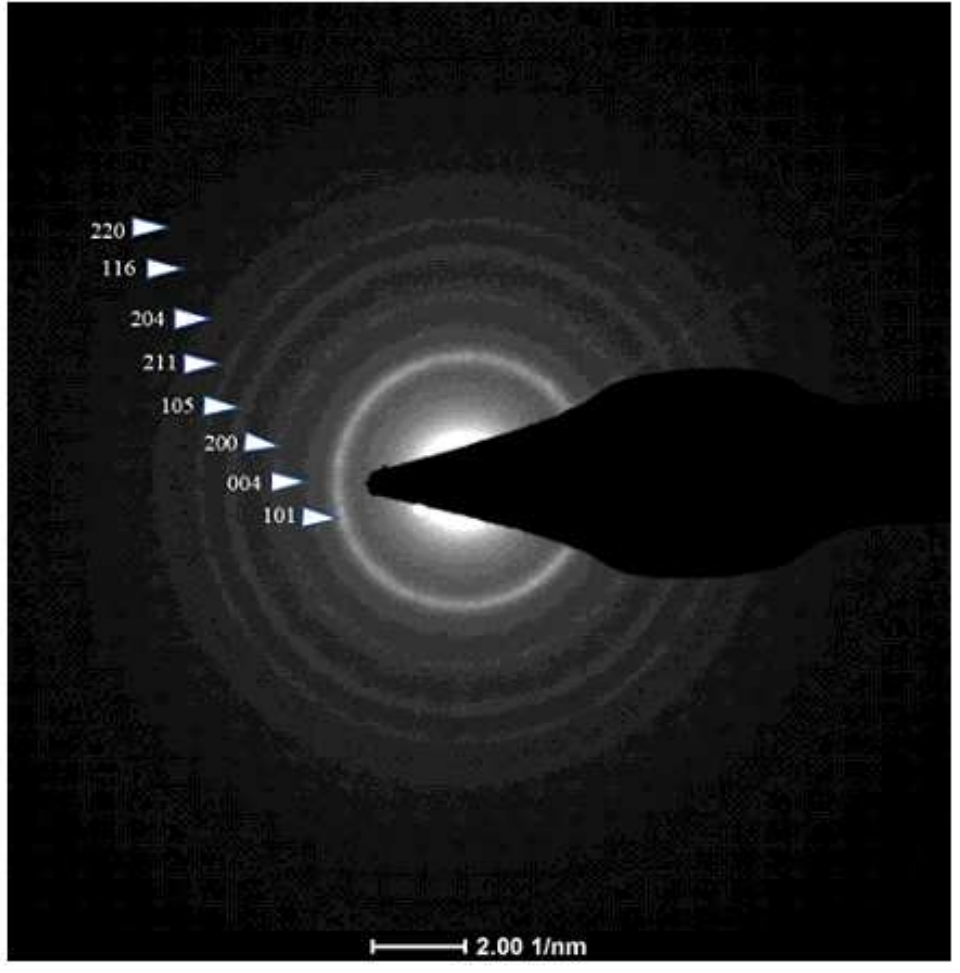

(b)

Figure 4

(a) TEM, and (b) SAED of TiO2 nanoparticles

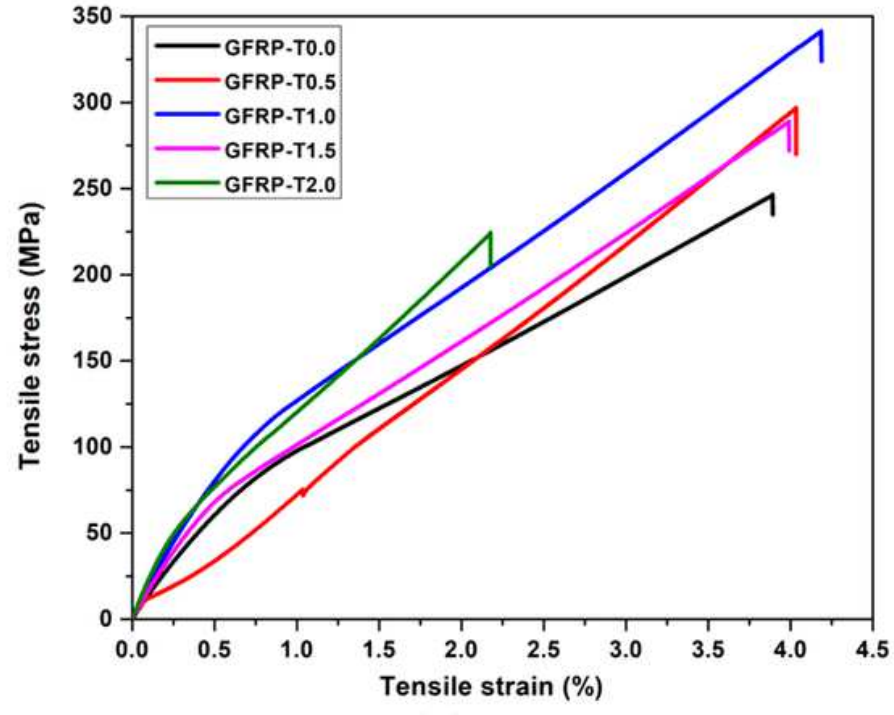

(a)

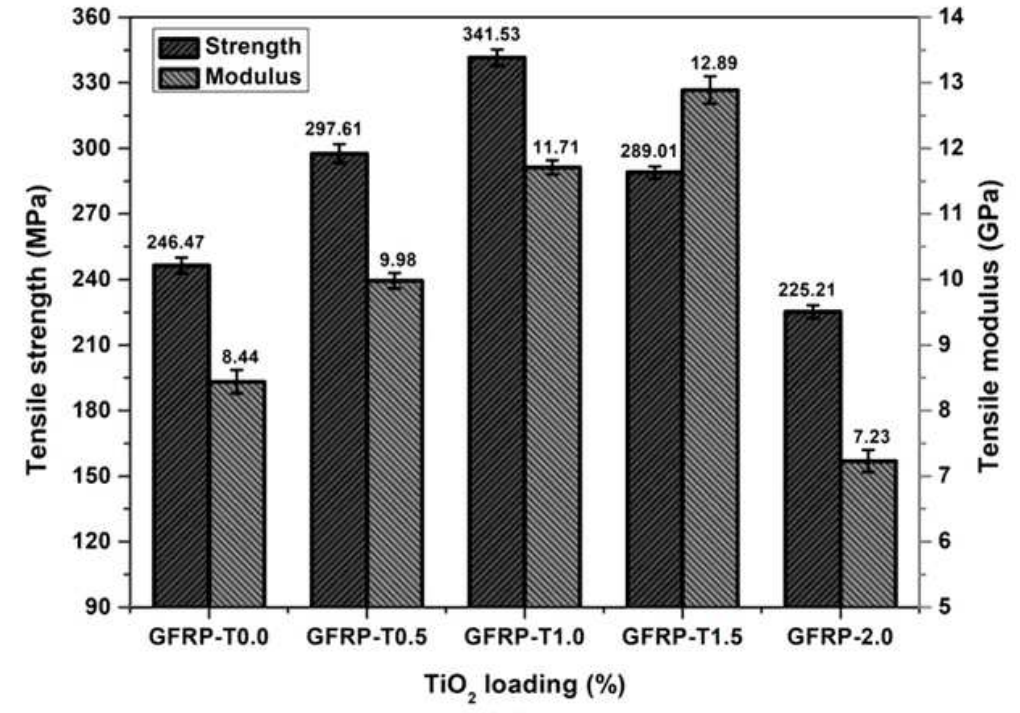

(b)

\section{Figure 5}

(a) Tensile stress-strain and (b) Comparative representation of tensile properties for developed composites 


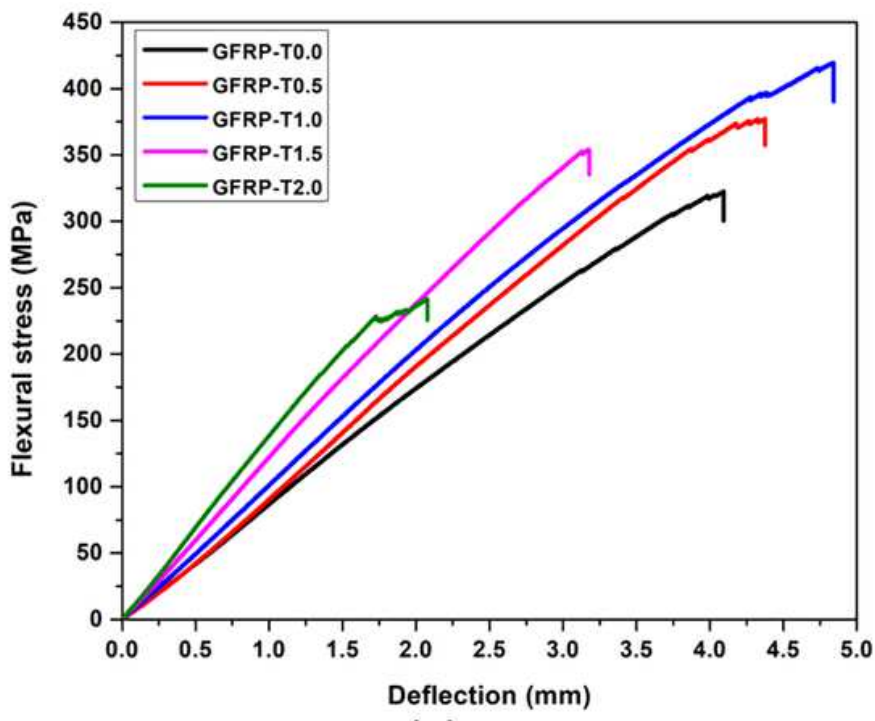

(a)

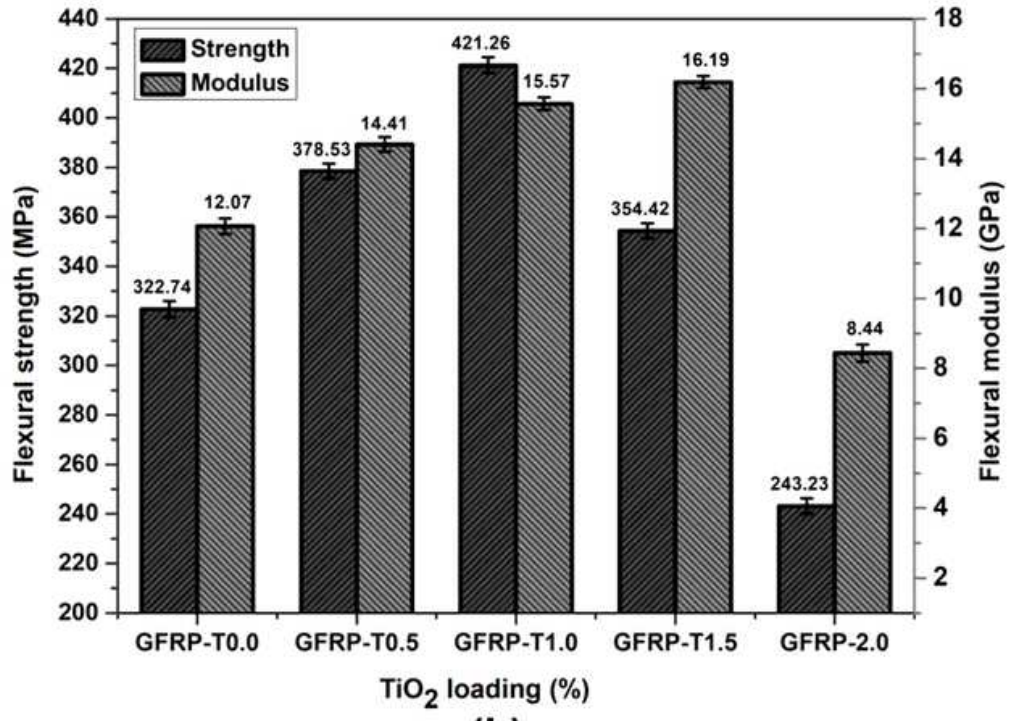

(b)

Figure 6

(a) Flexural stress-strain and (b) Comparative representation of flexural properties for developed composites

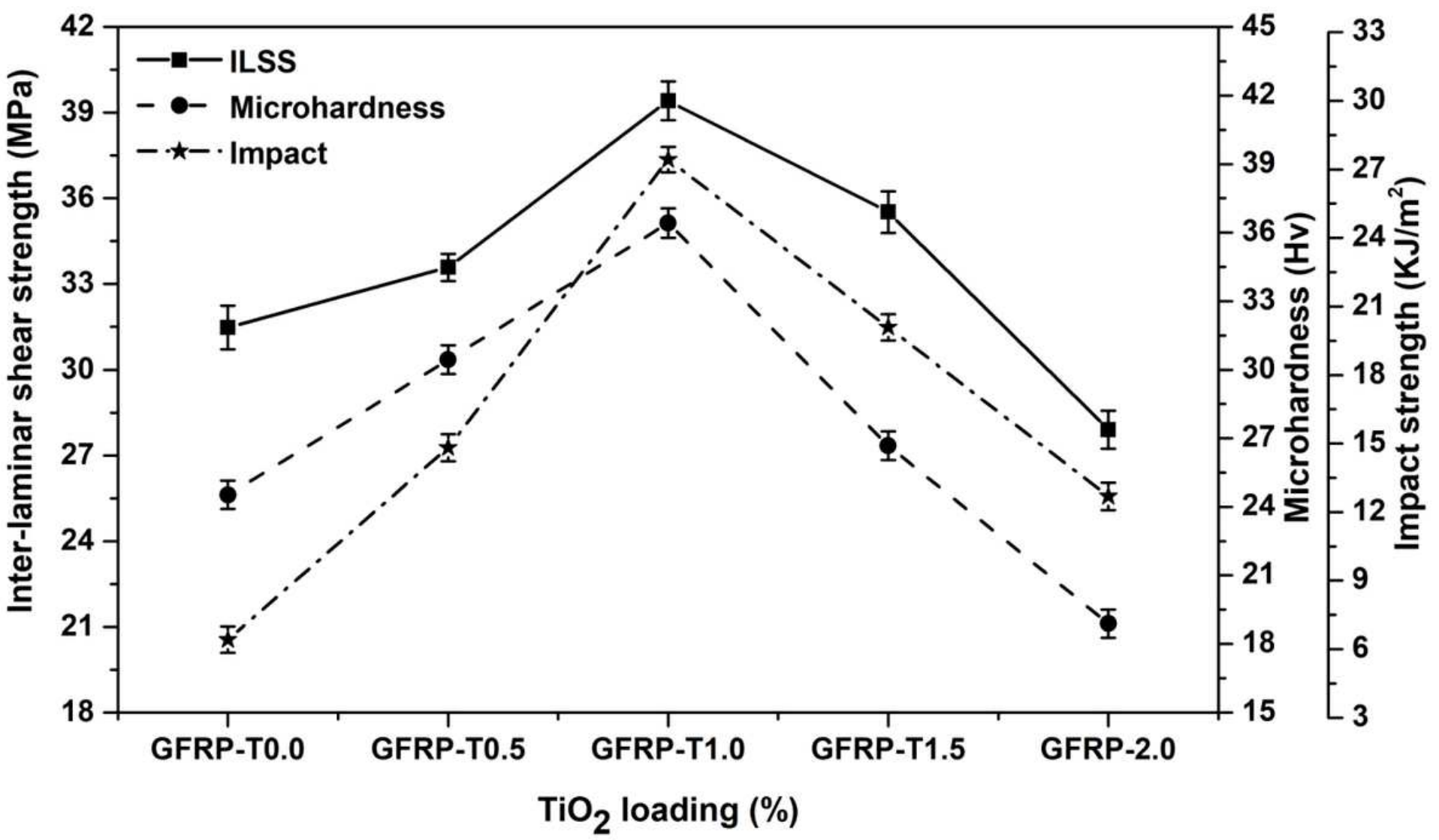


Figure 7

ILSS, micro-hardness and impact strength of developed composite laminates

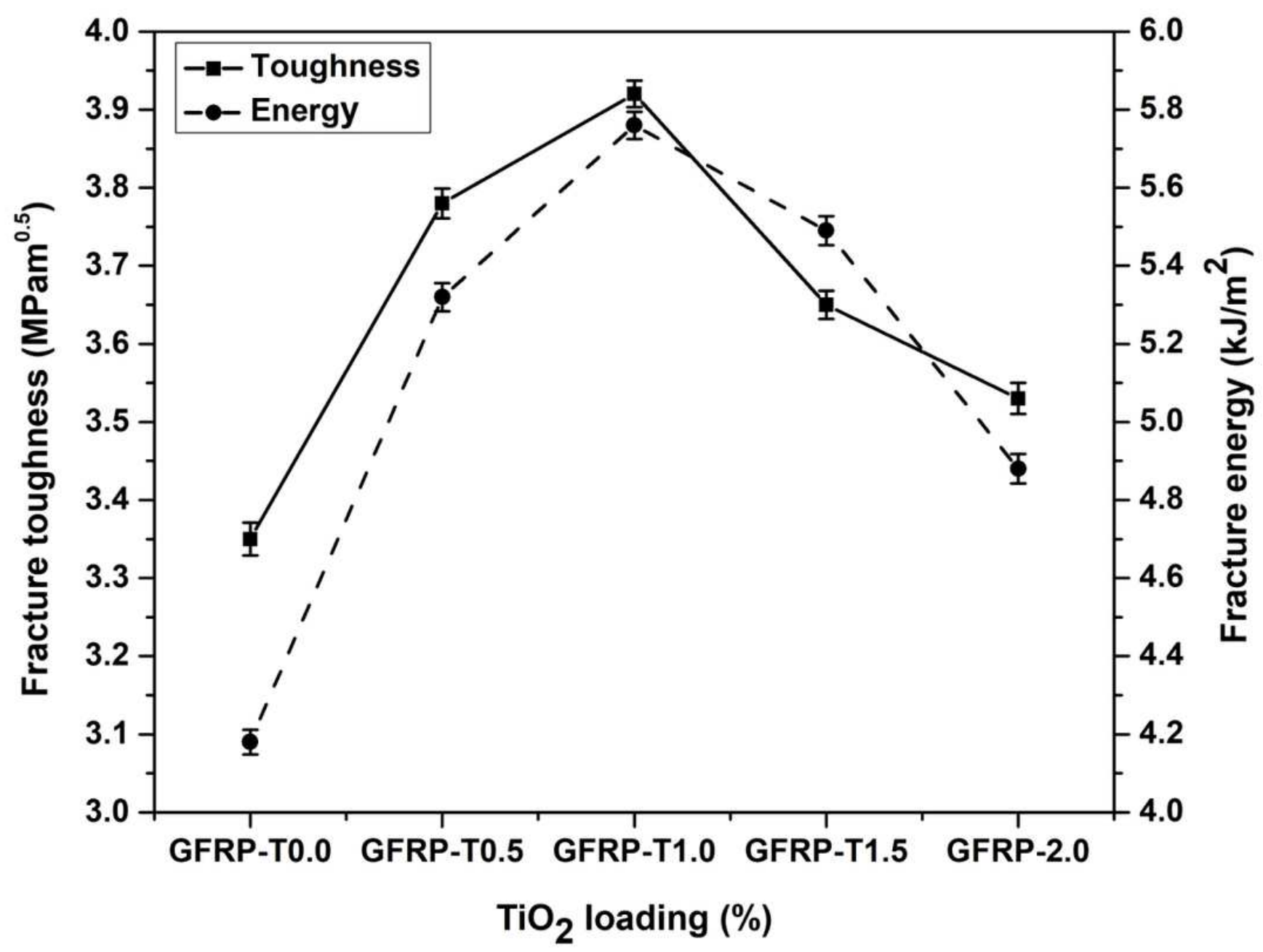

Figure 8

Fracture properties of developed composite laminates 


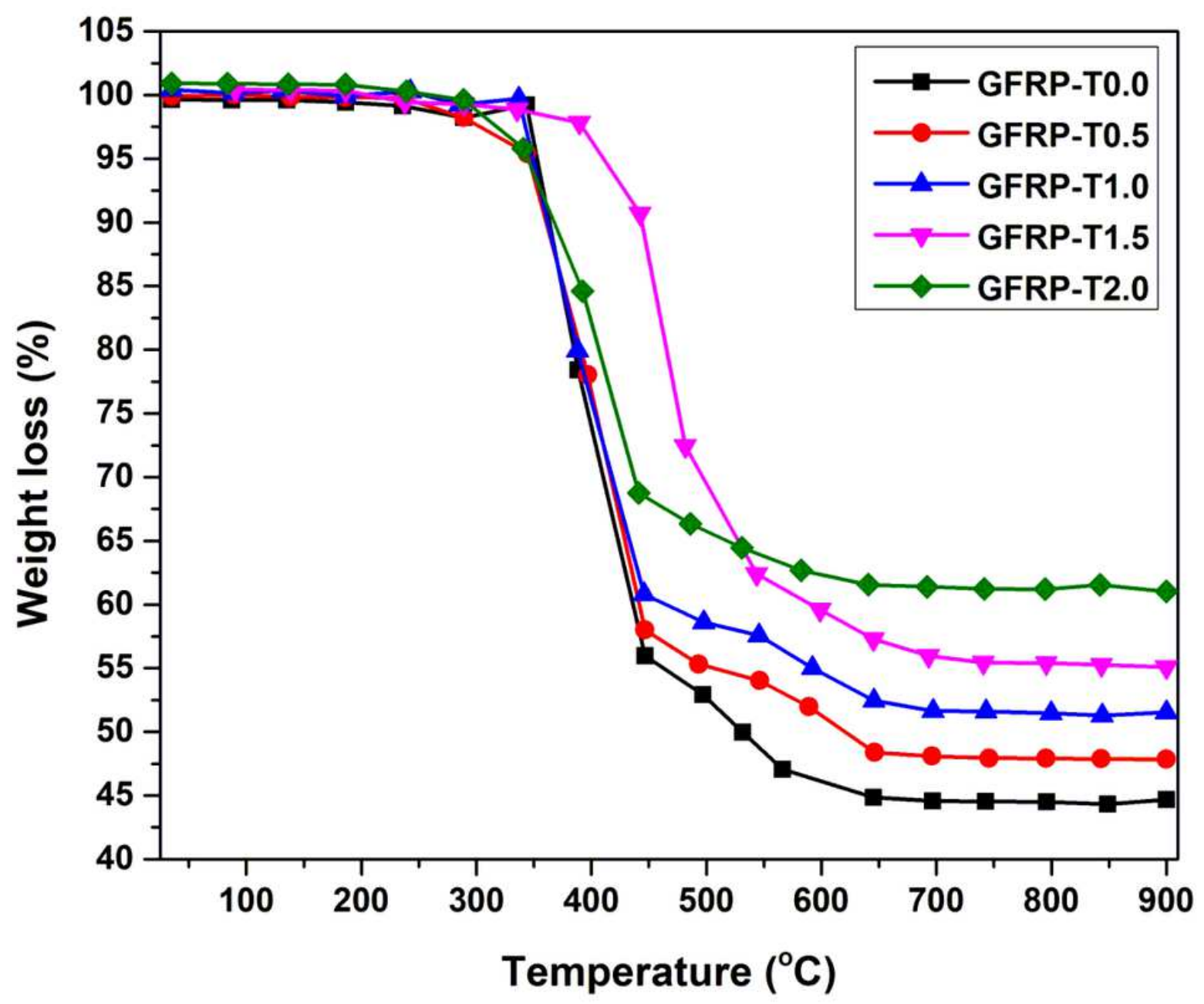

Figure 9

TGA of developed composite laminates 


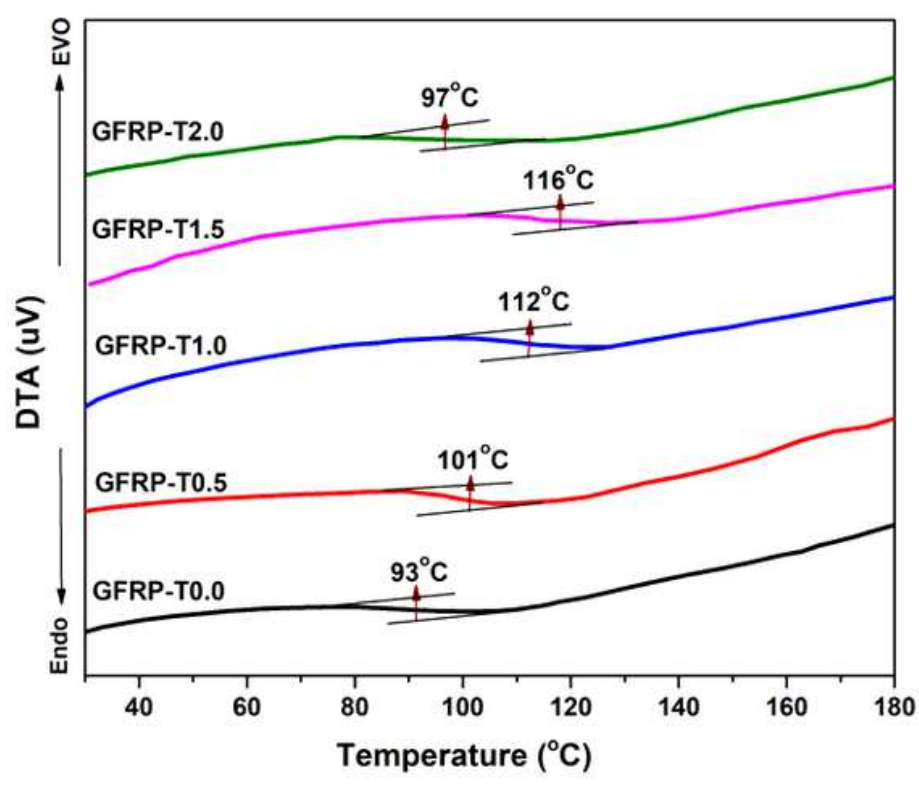

(a)

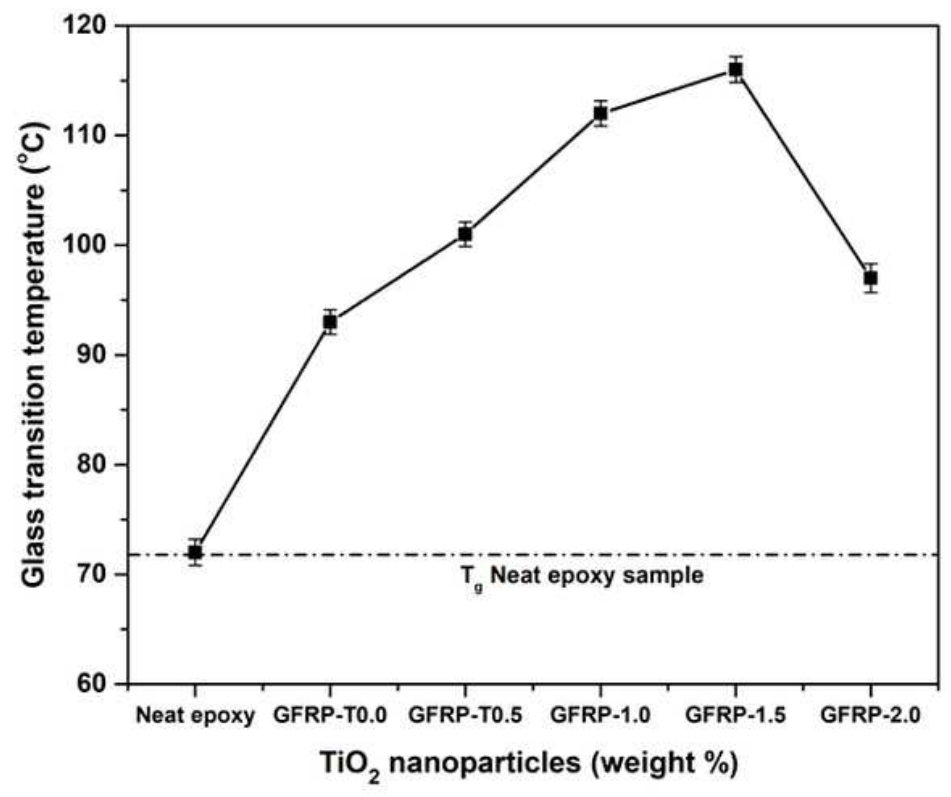

(b)

Figure 10

(a) DTA and (b) Tg at different weight fraction of developed composite laminates 


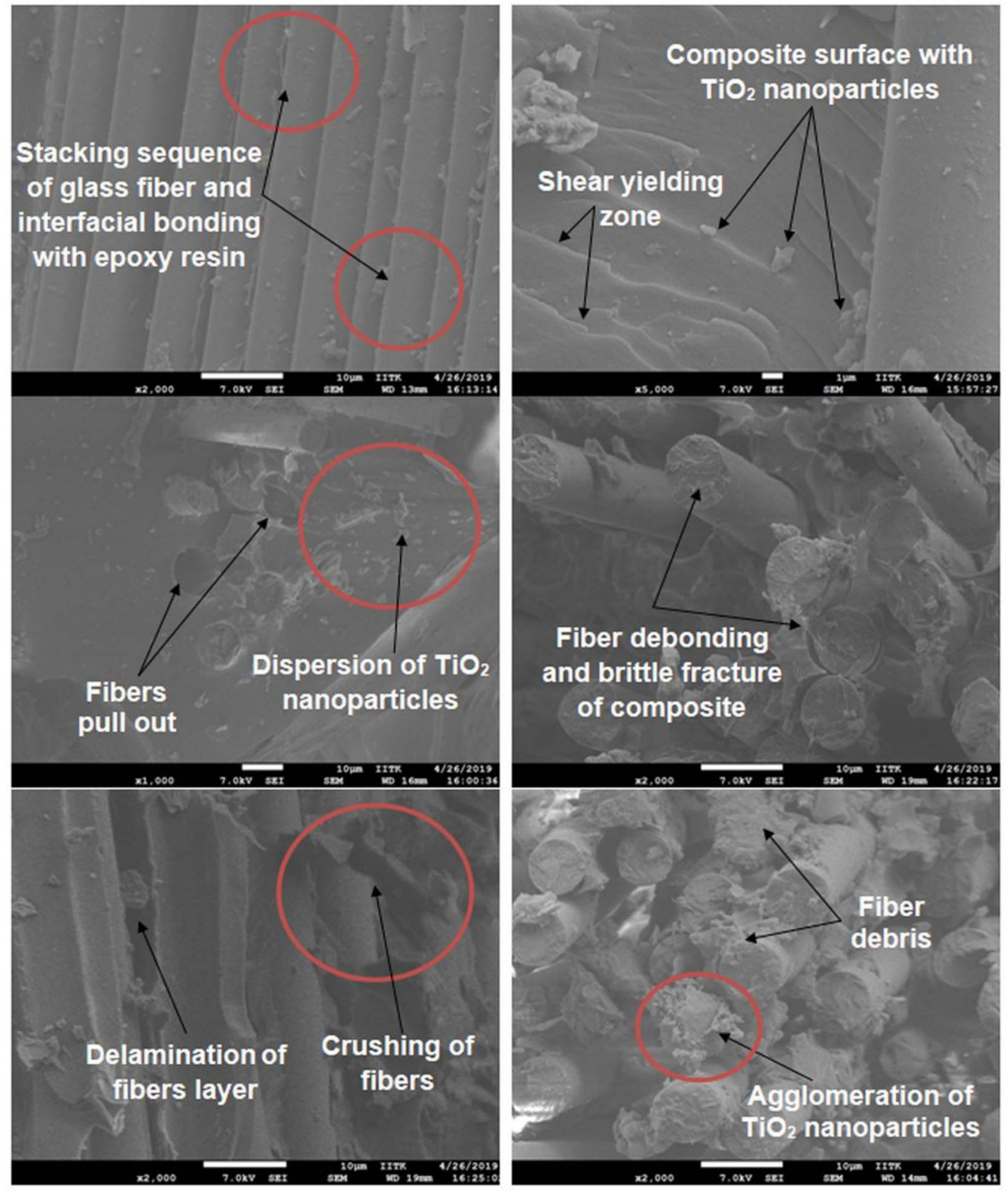

Figure 11

Morphology analyses at fracture surface of developed composite laminates. 